UNIVERSIDADE DE BRASÍLIA

FACULDADE DE TECNOLOGIA

DEPARTAMENTO DE ENGENHARIA ELÉTRICA

\title{
DESENVOLVIMENTO DE APLICATIVO COMPUTACIONAL PARA ESTUDOS DE ALÍVIO DE CARGA POR SUBFREQÜ̂̂NCIA
}

\author{
ALYSSON LUIDDI SANT'ANA QUINTANILHA \\ SALEM GOMES LEITE
}

ORIENTADOR: MAURO MOURA SEVERINO

BRASÍLIA/DF: JUNHO - 2005 
UNIVERSIDADE DE BRASÍLIA 

FACULDADE DE TECNOLOGIA DEPARTAMENTO DE ENGENHARIA ELÉTRICA

\author{
DESENVOLVIMENTO DE APLICATIVO \\ COMPUTACIONAL PARA ESTUDOS DE ALÍVIO \\ DE CARGA POR SUBFREQÜÊNCIA.
}

\title{
ALYSSON LUIDDI SANT'ANA QUINTANILHA \\ SALEM GOMES LEITE
}

PROJETO SUBMETIDO AO DEPARTAMENTO DE ENGENHARIA ELÉTRICA DA FACULDADE DE TECNOLOGIA DA UNIVERSIDADE DE BRASÍLIA COMO PARTE DOS REQUISITOS NECESSÁRIOS PARA A OBTENÇÃO DO TÍTULO DE ENGENHEIRO ELETRICISTA.

APROVADA POR:

Prof. Mauro Moura Severino, (ENE-UnB)

(Orientador)

Prof. Francisco Damasceno Freitas, (ENE-UnB)

Ricardo Marcelo Teixeira (Eletronorte)

BRASÍLIA/DF, JULHO - 2005 
FICHA CATALOGRÁFICA

QUINTANILHA, ALYSSON LUIDDI SANT'ANA

GOMES LEITE, SALEM

Desenvolvimento de Aplicativo Computacional para Estudos de Alívio de Carga por Subfreqüência. [Distrito Federal] 2005.

Universidade de Brasília. Faculdade de Tecnologia.

Departamento de Engenharia Elétrica.

\section{REFERÊNCIA BIBLIOGRÁFICA}

QUINTANILHA, ALYSSON L. S. e LEITE, SALEM G. (2005). Desenvolvimento de

Aplicativo Computacional para Estudos de Alívio de Carga por Subfreqüência.

Departamento de Engenharia Elétrica, Universidade de Brasília, Brasília, DF.

\section{CESSÃO DE DIREITOS}

AUTORES: Alysson Luiddi Sant'Ana Quintanilha e Salem Gomes leite

TÍTULO: Desenvolvimento de Aplicativo Computacional para Estudos de Alívio de Carga por Subfreqüência.

GRADUAÇÃO ANO: 2005

É concedida à Universidade de Brasília permissão para reproduzir cópias desta dissertação de graduação e para emprestar ou vender tais cópias somente para propósitos acadêmicos e científicos. Aos autores reservam outros direitos de publicação e nenhuma parte dessa dissertação de graduação pode ser reproduzida sem autorização por escrito dos autores.

Alysson Luiddi Sant'Ana Quintanilha SQS 403 Bl J apt.: 306

Cep 70237 - DF - Brasil
Salem Gomes Leite

CLN 404 B1. D apt.: 209

Cep 70845-540 - DF - Brasil 


\section{AGRADECIMENTOS}

A Deus, "Porque o Senhor dá a sabedoria, e da sua boca vem a inteligência e o entendimento".

Aos parentes, em especial aos pais, que nos forneceram oportunidades, incentivos e educação para alcançarmos nossos objetivos.

Aos amigos, que nos ajudaram, nos divertiram e nos aconselharam.

Aos colegas de trabalho na Eletronorte, que nos deram apoio e, com as suas experiências, nos orientaram.

Aos professores, que nos ensinaram e desafiaram. 


\section{RESUMO}

O objetivo deste trabalho é desenvolver um programa computacional que simule o comportamento da freqüência do sistema elétrico quando da perda de uma parte significativa da geração, com conseqüente desligamento coordenado de cargas.

Foi feito um estudo de um método iterativo para o cálculo da curva freqüência versus tempo, que foi usada na implementação do programa.

O programa foi feito na linguagem Delphi, por ser um software que possibilita o desenvolvimento de aplicativos com interface gráfica. Assim sendo, fornece um ambiente amigável e de fácil utilização para o usuário.

O resultado do programa é comparado com o de outros aplicativos semelhantes, mostrando resultados satisfatórios, de acordo com o objetivo proposto para sua elaboração.

Pode-se concluir que o programa se torna mais útil em circunstâncias em que a geração não tem reserva girante, ou seja, em que os reguladores de velocidade e de tensão não influenciarão na recuperação da freqüência para o seu valor de operação. Logo, ele será utilizado para simulação do "pior caso". Com isso, fornece dados para aperfeiçoamento em programas mais elaborados, em que mais dados são considerados. 


\section{COMPUTACIONAL PARA ESTUDOS DE ALÍVIO..................II}

\section{DE CARGA POR SUBFREQÜÊNCIA.........................................II}

Alysson Luiddi Sant'Ana Quintanilha...................................................ii

BRASÍLIA/DF, Julho - 2005 .............................................................ii

Quintanilha, Alysson Luiddi Sant'Ana..................................................................ii

Gomes Leite, Salem...............................................................................................ii

Quintanilha, Alysson L. S. e Leite, Salem G. (2005). Desenvolvimento de Aplicativo Computacional para Estudos de Alívio de Carga por Subfrequiência. Departamento de Engenharia Elétrica, Universidade de Brasília, Brasília, DF.

CESSÃO DE DIREITOS..................................................................................................iii

AUTORES: Alysson Luiddi Sant'Ana Quintanilha e Salem Gomes leite..................iii SQS 403 Bl J apt.: 306 CLN 404 Bl. D apt.: 209..........................................ii

3.2.1. Modelo de carga ................................................................................................9

4.3.1. Dados de entrada do programa em relação ao sistema......................................17

\section{OS RESULTADOS OBTIDOS ESTÃO RESUMIDOS NA}

TABELA ABAIXO.

\section{ANALISANDO-SE OS RESULTADOS, NOTA-SE, EM \\ TODAS AS SIMULAÇÕES, QUE MAIS GRUPOS FORAM \\ DESLIGADOS NO PROGRAMA PROPOSTO EM RELAÇÃO \\ AO FORNECIDO PELO ANATEM. ISTO SE DEVE, PRINCIPALMENTE, PELO FATO DE O ANATEM LEVAR EM CONSIDERAÇÃO NOS SEUS CÁLCULOS OS


6. CONCLUSÕES E SUGESTÕES PARA TRABALHOS FUTUROS.

POR MEIO DAS SIMULAÇÕES FEITAS NOS EXEMPLOS DO CAPÍTULO 5, NOTA-SE QUE OS DADOS DO PROGRAMA DESENVOLVIDO NESTE PROJETO SÃO COMPATÍVEIS COM OS ESPERADOS TEORICAMENTE. 35

EXISTE O DECRÉSCIMO DA FREQÜÊNCIA, QUANDO DA PERDA DE GERAÇÃO, E ESSA QUEDA É ATENUADA QUANDO HÁ DESLIGAMENTO DE BLOCOS DE CARGA. 35

OS EXEMPLOS APRESENTADOS, TAMBÉM, MOSTRAM QUE OS RESULTADOS SÃO COMPATÍVEIS COM OS INFORMADOS NOS PROGRAMAS QUE FORNECERAM OS DADOS PARA A COMPARAÇÃO.

COMO O PROGRAMA DESENVOLVIDO NÃO LEVA EM CONSIDERAÇÃO OS MODELOS DOS REGULADORES DAS MÁQUINAS, SEUS DADOS SERÃO MAIS PRECISOS QUANDO O SISTEMA ESTÁ SEM RESERVA GIRANTE....35

PODE-SE AFIRMAR QUE ESTE PROGRAMA SERÁ UMA FERRAMENTA ÚTIL NA ELABORAÇÃO DE ERACS, UMA VEZ QUE FORNECERÁ OS DADOS INICIAIS OU O "PIOR 
CASO” PARA A ANÁLISE E PARA OS AJUSTES POSTERIORES EM PROGRAMAS MAIS ELABORADOS..35

É PROPOSTA, PARA TRABALHOS FUTUROS, A IMPLEMENTAÇÃO, NO CÓDIGO DO PROGRAMA, DE MÉTODOS QUE PERMITAM A ENTRADA DOS MODELOS DOS REGULADORES DAS MÁQUINAS. ISSO AUMENTARIA SUA EFICIÊNCIA E UTILIDADE. ENTRETANTO, COMO JÁ EXISTEM PROGRAMAS COMO O ANATEM, QUE JÁ TRABALHA COM MODELOS DE REGULADORES E ESTES SÃO CONSIDERAVELMENTE COMPLEXOS, PODE SER INTERESSANTE QUE O PROGRAMA DESENVOLVIDO NESTE PROJETO NÃO USE TAIS MODELOS, VISTO QUE DIMINUIRÁ O ESFORÇO APLICADO EM SIMULAÇÕES MAIS PRECISAS, A FIM DE SE OBTER OS AJUSTES NECESSÁRIOS PARA CASOS MAIS PESSIMISTAS, NA IMPLEMENTAÇÃO DE UM ERAC, SENDO DE MAIOR UTILIDADE COMO UMA FERRAMENTA AUXILIAR PARA PROGRAMAS MAIS ELABORADOS.

MELHORIAS NA PARTE DE VISUALIZAÇÃO E IMPLEMENTAÇÃO DOS RESULTADOS PODERÃO SER FEITAS, À MEDIDA QUE SE DESENVOLVEM MAIS COMPONENTES PARA A LINGUAGEM DE 
PROGRAMAÇÃO DELPHI, QUE É A LINGUAGEM UTILIZADA NA ELABORAÇÃO DESTE PROGRAMA........35 REFÊRENCIAS BIBLIOGRÁFICAS......................................36

ANEXOS...................................................................................................37

ANEXO I - ALGORITMO DO PROGRAMA..............................38

PROGRAMA: CALCSUB..............................................................38 


\section{LISTA DE TABELAS}

Tabela 4.1 - Operação em regime de frequiência não nominal.

Tabela 5.1 - Dados de entrada para o exemplo proposto para comparação com o programa

Varf-5

Tabela 5.2 - Dados de ajuste dos relés para o exemplo proposto para comparação com o programa Varf-5.

Tabela 5.3 - Resumo dos resultados obtidos da simulação no programa Varf-5...............26

Tabela 5.4 - Resumo dos resultados obtidos da simulação no programa proposto.............26

Tabela 5.5 - Dados das máquinas da Usina Termoelétrica Santana...................................29

Tabela 5.6 - Dados das máquinas da Usina Hidroelétrica Coaracy Nunes........................29

Tabela 5.7 - Dados de entrada de geração para o exemplo 2 ..............................................30

Tabela 5.8 - Configuração de desligamento de carga do ERAC do Sistema Amapá...........31

Tabela 5.9 - Tempo total para abertura dos disjuntores....................................................

Tabela 5.10 - Perdas de geração que serão simuladas.........................................................32

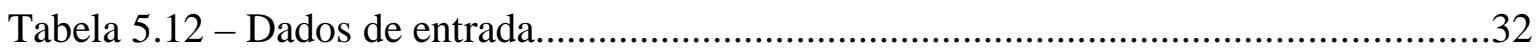

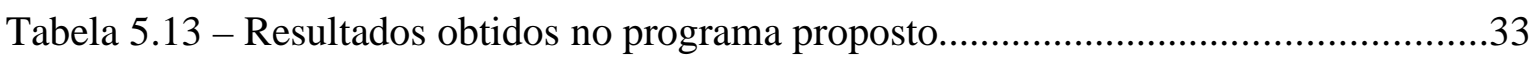




\section{LISTA DE FIGURAS}

Figura 2.1 - Perda de geração de 5\% (curva A) e de 40\% (curva B).....

Figura 2.2 - Sistema sem rejeição de carga (curva A) e com rejeição de $23 \%$ da carga

(curva B) para uma perda de $40 \%$ da geração total.............................................................

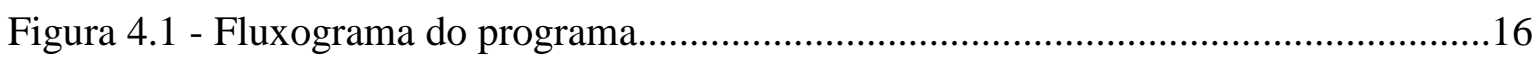

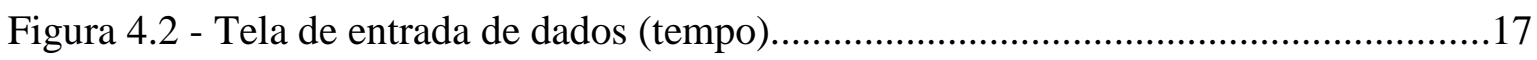

Figura 4.3 - Tela de entrada de dados (geração)................................................................ 18

Figura 4.4 - Tela de entrada de dados (carga)................................................................... 19

Figura 4.5 - Tela de entrada de dados (freqüência)............................................................19

Figura 4.6 - Tela de entrada de dados ajuste dos grupos de rejeição..................................21

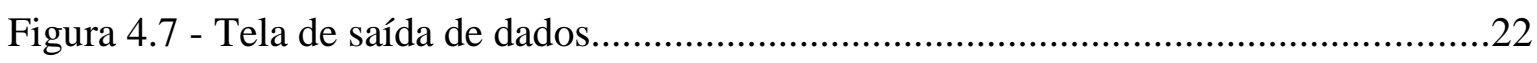

Figura 5.1 - Gráfico de comparação Varf com o programa proposto.................................27

Figura 5.2 - Mapa do Amapá com a representação do sistema elétrico...............................28

Figura 5.3 - Diagrama unifilar do sistema elétrico do Amapá..............................................30 


\section{LISTA DE SÍMBOLOS E ABREVIATURAS}

CEPEL - Centro de Pesquisas em Energia Elétrica

$D T$ - Constante de amortecimento da carga

$D L$ - Fator que depende da composição da carga

ECE - Esquema de Controle de Emergência

ERAC - Esquema de Rejeição Automática de Carga

$f$ - Freqüência

$f_{0}-$ Freqüência inicial

$F W$ - Primeira freqüência encontrada abaixo da freqüência de supervisão.

$F[\mathrm{~N}+1]$ - Freqüência para a próxima iteração

$G T$ - Geração total

$G R$ - Geração remanescente

$\mathrm{Hz}-\mathrm{Hertz}$

$H$ - Constante de inércia

ONS - Operador Nacional do Sistema Elétrico

$P R$ - Potência restante

$P C_{0}$ - Potência da carga inicialmente

$P G_{0}$ - Potência da geração inicialmente

SE - Subestação

$s-$ Segundos

$T C$ - Conjugado da carga

$T A$ - Conjugado elétrico

$T G$ - Conjugado da geração

$T C_{0}$ - Conjugado da carga inicial

$T G_{0}$ - Conjugado da geração inicial

$T C_{\mathrm{N}-1}$ - Conjugado da carga na iteração anterior

$T C_{\mathrm{N}}$ - Conjugado da geração na iteração

TX - Taxa de variação

TEMx - Tempo decorrido até o alcance da freqüência de supervisão do relé.

TEMPO $[\mathrm{N}+1]$ - Tempo decorrido na iteração atual

$t$ - Tempo

UGG - Unidade Geradora a Gás 
UGD - Unidade Geradora a Diesel

UGH - Unidade Geradora hidráulica

$\beta$ - Fator de sobrecarga

$f^{\prime}$ - Derivada da frequiência pelo tempo

$\theta$ - Ângulo elétrico do rotor da máquina síncrona

$\delta$ - Ângulo do rotor em relação a um eixo de referência

$\omega$ - Velocidade angular

$\omega_{0}$ - Velocidade angular inicial

$\Delta f$ - Variação (desvio) de freqüência

$\Delta t$ - Passo do método numérico 



\section{INTRODUÇÃO}

Algo muito importante em sistemas elétricos de potência é a freqüência dos mesmos, pois todos os elementos que constituem esses sistemas são feitos para atenderem ou usufruírem dela, a qual é previamente estabelecida com um valor fixo, no qual os sistemas elétricos devem operar.

Com a perda significativa de geração, provocada, por exemplo, por curtos-circuitos em linhas de transmissão que dão acesso às máquinas ou defeitos em equipamentos, ocorrerão perturbações no sistema, podendo submeter o sistema a afundamentos da freqüência.

Os elementos de proteção chamados relés de frequiência são ajustados para atuarem na ocorrência de variações na freqüência, a fim de protegerem os equipamentos, como geradores, bem como garantir o funcionamento do sistema elétrico em níveis aceitáveis, isto é, que foram pré-determinados conforme estudos técnicos específicos.

Uma grande perturbação, como uma perda significativa de geração, quando provoca o afundamento da frequiência do sistema elétrico, pode levar ao colapso total deste. Para tentar evitar este fenômeno, são utilizados esquemas de controle de emergência (ECEs), como o Esquema Regional de Alívio de Carga (ERAC).

Para a implementação de um ERAC, utilizam-se aplicativos computacionais para simulações de contingências do tipo perda de geração em um sistema elétrico. Esses programas, como o Anatem, que é um software desenvolvido pelo Centro de Pesquisas em Energia Elétrica (CEPEL), utilizam os dados elétricos do sistema, dados de máquina, bem como os modelos representando os reguladores de tensão e de velocidade dos geradores. No intuito de minimizar o esforço desenvolvido em tais aplicativos, no tocante à quantidade de simulações necessárias, elaborou-se o programa proposto neste projeto, sem a necessidade de se entrar com todos os dados elétricos do sistema e os modelos dos reguladores, fornecendo um resultado satisfatório e diminuindo consideravelmente o tempo de elaboração do ERAC. No entanto, este aplicativo é uma ferramenta auxiliar. Ele será utilizado tomando-se os dados de máquinas, de carga e prosseguindo com os ajustes dos relés de subfreqüência e do percentual de alívio de carga, para posteriormente serem aperfeiçoados em programas mais elaborados, como o Anatem.

O trabalho está assim estruturado: o capítulo 1 apresenta a introdução do trabalho; no capítulo 2, é apresentado um estudo sobre o equilíbrio carga-geração após a perda de 
geração; o capítulo 3 apresenta o desenvolvimento teórico para elaboração da curva freqüência versus o tempo; no capítulo 4, é proposto o aplicativo computacional para o estudo de alívio de carga por subfreqüência; o capítulo 5 consiste em exemplos da aplicação do programa proposto na resolução do problema para manter o equilíbrio cargageração após perda de geração; no capítulo 6, são apresentadas conclusões e sugestões para futuros trabalhos. 


\section{EQUILÍBRIO CARGA-GERAÇÃo APÓS A PERDA DE GERAÇÃo}

\section{[1]}

\subsection{PERDA DE GERAÇÃO}

Em um sistema elétrico estável, quando ocorre uma perturbação como a perda de um gerador, tem como uma de suas conseqüências o afundamento da freqüência desse sistema, sendo tal perda pequena ou significativa. Se a perturbação for pequena, as regulações próprias do sistema e primárias das máquinas remanescentes, com seus reguladores de velocidade, forçam a freqüência do sistema a voltar ao seu valor de regime ou a um valor próximo deste, o mais rápido possível, desde que haja reserva girante suficiente para manter o equilíbrio carga-geração. Se a perturbação no sistema for considerável, poderá ocorrer um afundamento rápido na freqüência, e como as respostas dos reguladores de velocidade são lentas, tipicamente acima de um segundo para a abertura máxima dos atuadores ou posicionamento máximo dos distribuidores, a freqüência do sistema poderá atingir valores que levem à atuação das proteções de subfrequiência das máquinas, desligando-nas. Assim, na ocorrência de grandes perturbações, causadas por perda de geração, faz-se necessária a rejeição de cargas para manter o equilíbrio carga-geração e diminuir a velocidade de queda da frequiência, levando os reguladores de velocidade a atuarem mais rápidos, forçando a subida da frequiência ao seu valor de regime ou a um valor próximo deste.

As Figuras 2.1 e 2.2 seguintes são simulações efetuadas no programa Anatem. A figura 2.1 mostra o comportamento da freqüência com o tempo de um sistema elétrico isolado após as simulações da perda de uma pequena e de uma grande geração correspondendo, respectivamente, a 5\% (curva A) e 40\% (curva B) em relação a geração inicial total do sistema analisado, sem alívio de carga. A curva A tem um afundamento da frequiência, mas esta retorna (sobe) ao um valor próximo do nominal, inicial. Isso porque a perda de geração é pequena e as regulações próprias do sistema e primárias das máquinas forçam esta subida. No caso da curva $\mathrm{B}$, o afundamento é tal que a frequiência não retorna ao seu valor inicial, nem próximo deste, uma vez que a perda de geração é considerável e os mecanismos de regulação não foram suficientes para forçar a subida da freqüência. 


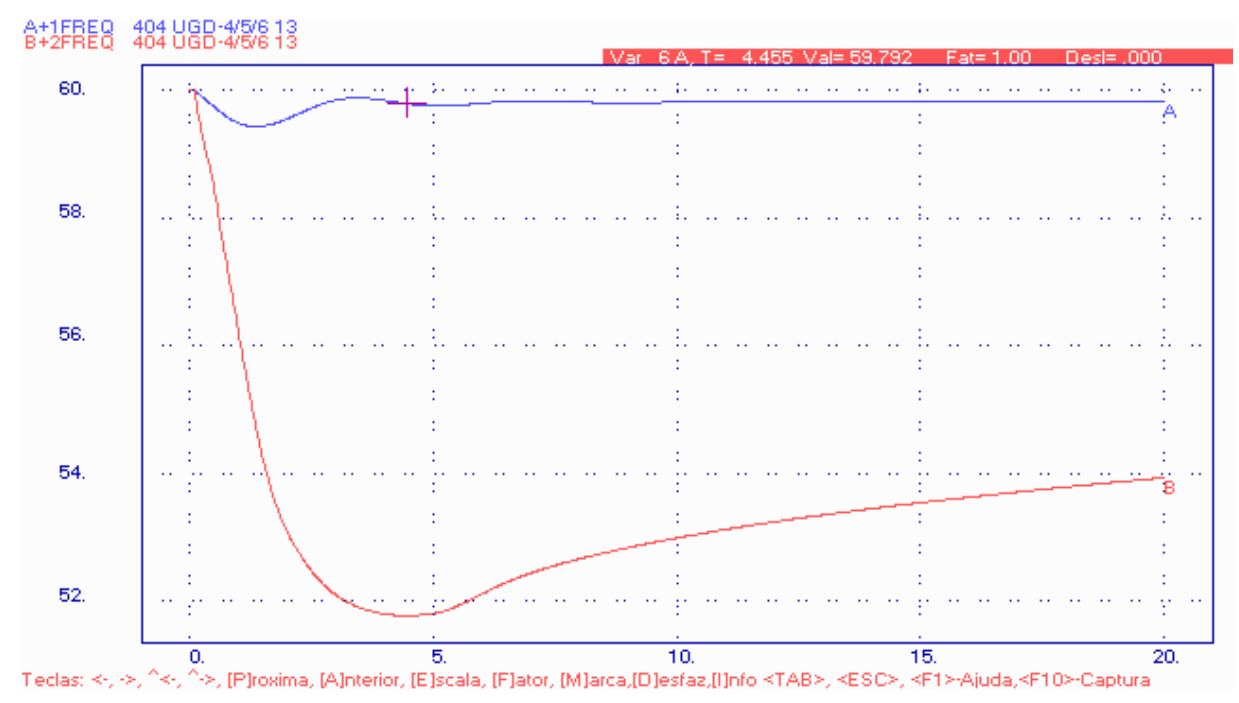

Figura 2.1 - Perda de geração de 5\% (curva A) e de 40\% (curva B)

A Figura 2.2 mostra o comportamento típico da freqüência após as simulações da perda de uma geração correspondendo a $40 \%$ da geração inicial total do sistema sem rejeição (curva A) e com rejeição (curva B) de 23\% da carga, também em relação a geração inicial total. A curva A desta figura é a curva B da figura 2.1. Aqui, nota-se que o alívio de carga força a uma subida da frequiência, quando os mecanismos de regulação não são suficientes.

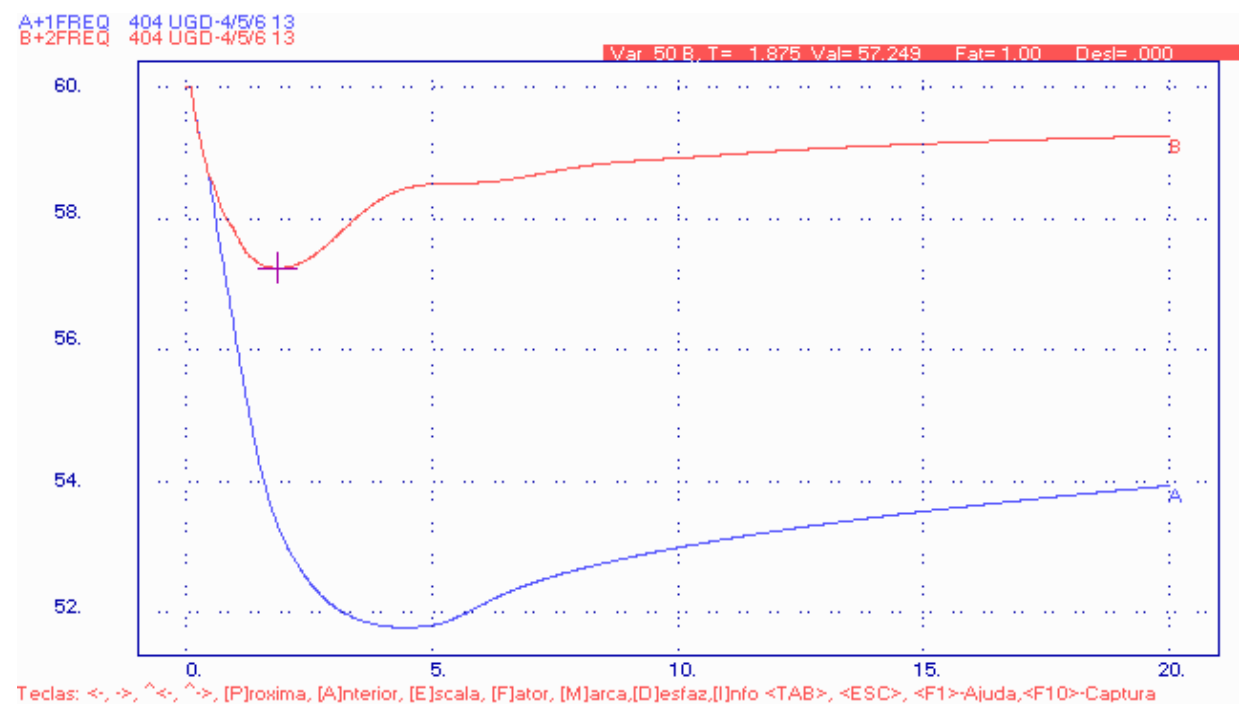

Figura 2.2 - Sistema sem rejeição de carga (curva A) e com rejeição de $23 \%$ da carga (curva B) para uma perda de $40 \%$ da geração total.

O problema a ser resolvido é manter o equilíbrio carga-geração de um sistema elétrico, após a perda de um ou mais geradores, fazendo uma retirada coordenada de carga, e não permitindo que na queda da freqüência do sistema esta ultrapasse as faixas 
permissíveis de freqüências abaixo da nominal ou a frequiência mínima permitida para o sistema elétrico analisado.

\subsection{REJEIÇÃO DE CARGA}

As rejeições de carga devem ser feitas segundo um esquema de controle de emergências (ECE), que atua quando acontecem grandes perturbações no sistema elétrico, como, por exemplo, a perda significativa de geração em um sistema elétrico.

Um ECE muito utilizado nos sistemas isolados é o esquema de rejeição automática de carga ou esquema regional de alívio de carga, ERAC, utilizando relés de subfreqüência. Neste tipo de ECE, a freqüência do sistema elétrico é monitorada. Assim, se ocorrer uma perda de geração que leve a freqüência do sistema a cair abaixo de um valor préestabelecido, ou a cair com uma velocidade acima, também, de um valor pré-estabelecido, o esquema atuará, retirando carga do sistema elétrico para compensar a perda de geração, fazendo com que o sistema elétrico restabeleça a freqüência nominal. Este procedimento preserva os geradores remanescentes de danos ou desligamentos por subfreqüência, e evita o colapso total no fornecimento de energia ao sistema elétrico.

Isso pode ser obtido por meio do desligamento rápido e coordenado de cargas. Como retirar carga do sistema é sempre uma ação indesejável, o trabalho de minimizar o montante de carga é muito importante e deve ser bastante criterioso.

O esquema utilizado para essa finalidade pode ser constituído de relés de taxa de variação de frequiência e relés de freqüência absoluta que, instalados em pontos estratégicos do sistema, desliguem automaticamente alimentadores pré-selecionados, evitando que a freqüência do sistema alcance valores considerados críticos, e assim restabelecer o estado de equilíbrio carga-geração.

Nos sistemas elétricos isolados, o impacto da perda de geração muitas vezes representa um percentual relativamente elevado da demanda total do sistema, o que, associado ao aspecto da inércia remanescente dos geradores ser relativamente baixa, faz com que o aspecto dinâmico mais relevante esteja associado ao desempenho dos esquemas regionais por alívio de carga por subfreqüência.

Logo, para resolver o problema de manter o equilíbrio carga-geração, deve-se saber como se comporta a frequiência do sistema elétrico em questão para determinadas contingências, como a perda de um ou mais geradores e, a partir desta informação, propor a rejeição coordenada e otimizada de determinados blocos de carga em função da taxa de 
variação da frequiência e da freqüência absoluta do sistema elétrico para o restabelecimento do equilíbrio carga-geração. 


\section{CURVA FREQÜÊNCIA VERSUS TEMPO}

\subsection{INTRODUÇÃO}

Como foi visto, é preciso monitorar a frequiência do sistema para a atuação do ERAC. Isso pode ser feito por meio da curva da frequiência em função do tempo.

O desequilíbrio no sistema, provocado inicialmente por uma perda súbita de parte da geração ou linhas de interligação, produz variações na curva freqüência pelo tempo, que também sofre variações bruscas quando são desligados blocos de cargas.

Sempre que ocorre uma mudança súbita no valor de carga, a taxa de variação $\frac{d f}{d t}$ sofre uma modificação, e a curva frequiência pelo tempo muda bruscamente a sua direção.

Para análise deste sistema em desequilíbrio, tornam-se necessárias as equações para o cálculo da curva freqüência pelo tempo.

\subsection{DETERMINAÇÃO DA CURVA FREQÜÊNCIA VERSUS TEMPO POR MEIO DAS EQUAÇÕES DE CÁLCULO DIRETO}

Um estudo bastante detalhado sobre este assunto foi publicado por Dalziel e Steinback [2].

Nesse trabalho, os autores demonstram equações que permitem determinar diretamente o tempo que um sistema desequilibrado leva para atingir uma determinada freqüência.

Admitiu-se que a curva real freqüência pelo tempo fica compreendida entre dois limites correspondentes às seguintes hipóteses: O conjugado de carga não depende da freqüência e é constante (equação (3.1)) e o conjugado de carga é proporcional à frequiência (equação (3.2)). [3]

$$
\begin{aligned}
& T C=T C_{0} \\
& T C=T C_{0} \times \frac{f}{f_{0}}
\end{aligned}
$$

Em que:

$f$ é a freqüência, em hertz $(\mathrm{Hz})$;

$f_{0}$ é a freqüência inicial, em hertz $(\mathrm{Hz})$; 
$T C$ é o conjugado elétrico da carga, que é calculado encontrado através da equação:

$$
T A=T G-T C
$$

Com:

$T A$ sendo o conjugado acelerante, em p.u;

$T G$ o conjugado mecânico da geração, em p.u.

As equações foram deduzidas independentemente para cada uma das hipóteses acima [3].

Para hipótese da equação 3.1, a equação encontrada foi:

$$
t=\frac{2 H}{f_{0} \times T C_{0}} \times\left[f_{0}-f+2,30 \frac{f_{0}}{\beta} \times \log \left|\frac{\frac{f_{0}}{\beta}-f}{\frac{f_{0}}{\beta}-f}\right|\right]
$$

Já para a hipótese da equação 3.2, a equação encontrada é:

$$
t=\frac{2,30 H}{T C_{0}} \times \log \left|\frac{f_{0}^{2}-\frac{f_{0}^{2}}{\beta}}{f_{0}^{2}-\frac{f_{0}^{2}}{\beta}}\right|
$$

Em que:

$t$ é o tempo dado em segundos;

$H$ é a constante de inércia em p.u., na mesma base da geração remanescente;

$\beta$ que é o fator de sobrecarga.

A constante de inércia $(H)$ é a relação entre a energia cinética da máquina e sua potência nominal, correspondendo ao tempo necessário para a máquina sair do repouso e atingir a velocidade síncrona quando se aplica em seus terminais a sua potência aparente nominal [4].

O fator $\beta$ é definido como a relação entre os conjugados ou as potências da carga e da geração no instante inicial da perturbação [3].

$$
\beta=\frac{T C_{0}}{T G_{0}}=\frac{P C_{0}}{P G_{0}}
$$

Já no trabalho desenvolvido por Berdy [5], é deduzida a seguinte equação, que permite determinar a frequiência em função do tempo [3]:

$$
f^{\prime}=\frac{T A}{D T} \times\left|1-e^{-\left(\frac{D T}{2 H}\right) t}\right|
$$


Em que:

$f^{\prime}$ é a variação da frequiência, em p.u., na mesma base de $f_{0}$;

$T A$ é o conjugado acelerante, em p.u., na mesma base da geração remanescente;

$D T$ é o fator de amortecimento total;

$H$ é a constante de inércia do sistema em p.u., cuja base é a geração remanescente.

O valor de $f^{\prime}$ é negativo quando a freqüência está diminuindo.

O valor da freqüência, em hertz, é encontrado fazendo [3] [4]:

$$
f=f_{0}+f^{\prime} \times f_{0}
$$

O valor de $D T$ é calculado pela equação [3]:

$$
D T=T G+(D L-1) \times T C
$$

$D L$ é o fator que depende da composição da carga e normalmente é estimado ou determinado experimentalmente. Pode também ser chamado de constante de amortecimento.

\subsubsection{Modelo de carga}

Geralmente, a representação da carga de uma subestação é feita por um modelo composto que considera parcelas de carga, como a iluminação incandescente, que apresentam um comportamento de variação da potência com o quadrado da tensão e são, dessa forma, denominadas cargas tipo impedância constante. Cargas como os motores, que não variam significativamente suas potências com a tensão, são chamadas cargas tipo potência constante. Outras cargas, como os consumidores eletrointensivos (produção de alumínio), em regime permanente, variam linearmente com tensão e são denominadas cargas tipo corrente constante [1].

O procedimento-padrão para identificar o modelo de uma carga é realizar testes e medições específicas, mas, devido às dificuldades de execução destes testes e medições nas diversas subestações de um sistema elétrico, recorre-se a outros métodos, tais como o levantamento das características das cargas com base na sua composição por classe de consumidores, bem como na análise de determinadas ocorrências registradas [1].

Alguns tipos de carga, como a dos consumidores eletrointensivos, ou outros consumidores especiais, necessitam de modelos bem mais elaborados, baseados na modelagem matemática do processo industrial usado pelo consumidor, nos registros de 
medições especificas, como as distorções harmônicas e análise das respostas a distúrbios involuntários ou voluntários, como curtos-circuitos [1].

A equação (3.7) é valida para uma variação da freqüência partindo do valor nominal [3].

Quando ocorre alguma descontinuidade como, por exemplo, o desligamento de um bloco de carga, passa-se para uma nova curva exponencial.

Neste caso ainda vale a equação (3.7), porém é necessário determinar novos valores de $T G$ e $T C$ para a freqüência na qual ocorreu a descontinuidade .

Comparando os dois métodos mencionados acima, verifica-se que as equações de Dalziel e Steinback [2] têm a vantagem de fornecer o tempo em função da frequiência, o que é mais prático em cálculos de esquemas de conservação de carga onde se deseja saber em que ponto será atingida uma determinada frequiência. Por outro lado, essas fórmulas somente determinam as curvas correspondentes aos dois casos extremos (conjugado da carga constante ou proporcional à frequiência), que limitam a faixa na qual se verificam os valores práticos [3].

Já a equação deduzida no trabalho de Berdy [5] permite utilizar qualquer coeficiente de variação da carga com a freqüência, porém exige extrapolações para determinação do tempo correspondente a uma determinada freqüência [3].

\subsection{DETERMINAÇÃO DA CURVA FREQÜÊNCIA VERSUS TEMPO POR MEIO DAS EQUAÇÕES DE CÁLCULO “PASSO-A-PASSO"}

Para utilização em aplicativos computacionais, métodos de cálculo "passo-a-passo" são mais adequados.

Um método de cálculo "passo-a-passo" da curva freqüência versus tempo é apresentado abaixo e foi utilizado na implementação do programa apresentado neste projeto.

Seja $\theta$ o ângulo elétrico do rotor de uma máquina síncrona, em relação a uma referência fixa, e $\delta$ o ângulo deste rotor em relação a um eixo de referência que gira com a velocidade síncrona $\omega_{0}[3]$.

Então:

$$
\begin{aligned}
& \theta=\delta+\omega_{0} t \\
& \delta=\theta-\omega_{0} t
\end{aligned}
$$


Derivando em relação ao tempo:

$$
\frac{d \delta}{d t}=\frac{d \theta}{d t}-\omega_{0}
$$

$\mathrm{Ou}$,

$$
\frac{d \delta}{d t}=\omega-\omega_{0}
$$

Derivando novamente em relação ao tempo:

$$
\frac{d^{2} \delta}{d t^{2}}=\frac{d \omega}{d t}
$$

Como $\omega=2 \pi f$, pode-se escrever:

$$
\frac{d^{2} \delta}{d t^{2}}=2 \pi \times \frac{d f}{d t}
$$

$\mathrm{Ou}:$

$$
\frac{d f}{d t}=\frac{1}{2 \pi} \times \frac{d^{2} \delta}{d t^{2}}
$$

Por outro lado, temos a equação do movimento dos rotores de máquinas elétricas:

$$
T A=\frac{d^{2} \delta}{d t^{2}} \times \frac{H}{\pi f_{0}}
$$

$\mathrm{Ou}:$

$$
\frac{d^{2} \delta}{d t^{2}}=\frac{\pi f_{0}}{H} \times(T G-T C)
$$

Onde:

$T G$ e $T C$ são, respectivamente, os conjugados da geração e da carga em p.u. que variam em função da freqüência.

A Equação (3.18), diminuída do fator de amortecimento da carga $D T\left(f-f_{0}\right)$, é conhecida como equação de balanço ou swing:

$$
\frac{d^{2} \delta}{d t^{2}}=\frac{\pi f_{0}}{H}\left[T A-D T\left(f-f_{0}\right)\right]
$$

O termo $D T\left(f-f_{0}\right)$ representa a variação da carga com a freqüência, caracterizando a regulação própria ou auto-regulação do sistema. Assim, desvios negativos da frequiência resultam em decréscimo da carga e vice-versa. Um valor de $D T=2$ significa que uma variação de $1 \%$ na frequiência causa uma variação de $2 \%$ na carga [1]. Esse termo pode ser incorporado ao termo da potência elétrica da carga conforme indicado na equação (3.21). 
Substituindo (3.18) em (3.16) tem-se:

$$
\frac{d f}{d t}=\frac{f_{0}}{2 H} \times(T G-T C)
$$

Essa equação diferencial é a base do programa proposto do projeto, onde TG e TC são proporcionais à frequiência e são dados por:

$$
\begin{aligned}
& T C=T C_{0} \times\left(\frac{f}{f_{0}}\right)^{D T-1} \\
& T G=T G_{0} \times \frac{f_{0}}{f}
\end{aligned}
$$




\section{APLICATIVO COMPUTACIONAL PROPOSTO PARA O ESTUDO DE ALÍVIO DE CARGA POR SUBFREQÜÊNCIA}

\subsection{INTRODUÇÃO}

Neste capítulo será apresentado um método computacional para o cálculo da curva frequiência pelo tempo.

Esta curva estará sujeita a variações, caso ocorra queda na geração ou queda na carga. Com isso, pode-se simular o sistema em desequilíbrio, por perda de geração, e o que ocorre com o mesmo quando são desligados blocos de carga.

\subsection{DETERMINAÇÃO DA CURVA FREQÜÊNCIA VERSUS TEMPO NO PROGRAMA}

A resolução da equação diferencial (3.20) pode ser feita por vários métodos numéricos. Com os intervalos de tempo que serão utilizados no programa, verifica-se que o Método de Euler Simples é o recomendado, pois gera erros aceitáveis e aproximados aos de métodos mais elaborados como o do Euler Modificado [3].

O Método de Euler Simples é feito para pequenos intervalos $d t$ nos quais:

$$
f_{N}=f_{N-1}+\left.\Delta f\right|_{N-1} ^{N}
$$

Sendo que:

$$
\left.\Delta f\right|_{N-1} ^{N}=\Delta t \times\left.\frac{d f}{d t}\right|_{N-1} ^{N}
$$

Onde $\Delta t$ é o passo do método de Euler simples.

Substituindo (3.20) em (3.22) e usando o resultado assim obtido em (3.21), tem-se a equação que determina a freqüência no instante $t_{N}$, em função dos valores de $f, T G$ e $T C$, no instante $t_{N-1}$.

$$
f_{N}=f_{N-1}+\frac{f_{0}}{2 H} \times\left(T G_{N-1}-T C_{N-1}\right) \Delta t
$$

$T G$ e $T C$ são admitidos constantes no intervalo $t_{N-1}$ a $t_{N}$, porém o seu valor tem que ser recalculado para a nova frequiência no fim deste intervalo, de acordo com as seguintes equações: 


$$
\begin{aligned}
& T G_{N}=T G_{N-1}\left|\frac{f_{N-1}}{f_{N}}\right| \\
& T C_{N}=T C_{N-1}\left|\frac{f_{N}}{f_{N-1}}\right|^{D T-1}
\end{aligned}
$$

Como pode ser verificado na equação (4.3), o programa desenvolvido calculará as freqüências em diversas iterações "N".

O número dessas iterações dependerá do valor do passo $\Delta t$.

Para cada frequiência calculada, novos valores de TC e TG serão calculados e esses, por sua vez, gerarão um novo valor da frequiência.

Essas iterações constituem o "corpo" principal do programa.

\subsection{UTILIZANDO A CURVA FREQÜÊNCIA VERSUS TEMPO DO PROGRAMA, NA RESOLUÇÃO dO PROBLEMA DE MANTER O EQUILÍbRIO CARGA- GERAÇÃO APÓS PERDA DE GERAÇÃO}

Como visto anteriormente, um sistema em desequilíbrio, provocado inicialmente por uma perda súbita de parte da geração ou linha de interligação, também sofre variações bruscas quando são desligados blocos de carga.

Isso é comprovado ao se analisar o valor do conjugado da carga (TC) no instante inicial e no instante logo após o desligamento de um bloco de carga.

O valor inicial de TC para o cálculo da primeira iteração do programa será dado pela equação:

$$
T C_{0}=\frac{G T}{G R}
$$

Em que:

GT é o despacho total de geração da área estudada.

GR é a geração restante após a perda de uma porcentagem da geração total.

Como se pode perceber, o dado inicial para o conjugado da carga $\left(T C_{0}\right)$ é igual à sobrecarga imposta ao sistema. Isso mostra que a equação (4.3) é influenciada pela perda de geração.

As próximas iterações do programa calcularão a curva freqüência versus tempo utilizando as equações (4.4), (4.5) e (4.6). 
As simulações de desligamentos de blocos de carga são feitas através de ajustes de relés, que podem ser de taxa de variação ou de freqüência absoluta.

Quando a freqüência, calculada pela equação (4.3), do programa fica abaixo da ajustada pelo relé, o bloco de carga associado a esse relé é desligado. Nesse momento, é recalculado o valor de TC, com a nova configuração de carga, através da equação:

$$
T C_{N+1}=T C_{N} \times\left[\left(\frac{F[n+1]}{F[n]}\right)^{D T-1}-\frac{P R}{100} \times \frac{G T}{G R}\left(\frac{F[n+1]}{F I}\right)^{D T-1}\right]
$$

Onde PR é a porcentagem da carga desligada referente ao respectivo grupo. Isso garante que a equação (4.3) é influenciada pela perda de carga. Dessa forma, é possível garantir que a frequiência do sistema estudado decairá após uma perda de parte de sua demanda de geração e que ele crescerá quando uma parte de sua carga for desligada.

O algoritmo estruturado do programa é apresentado no Anexo I, e um fluxograma simplificado do programa é apresentado na figura seguinte (4.1). 


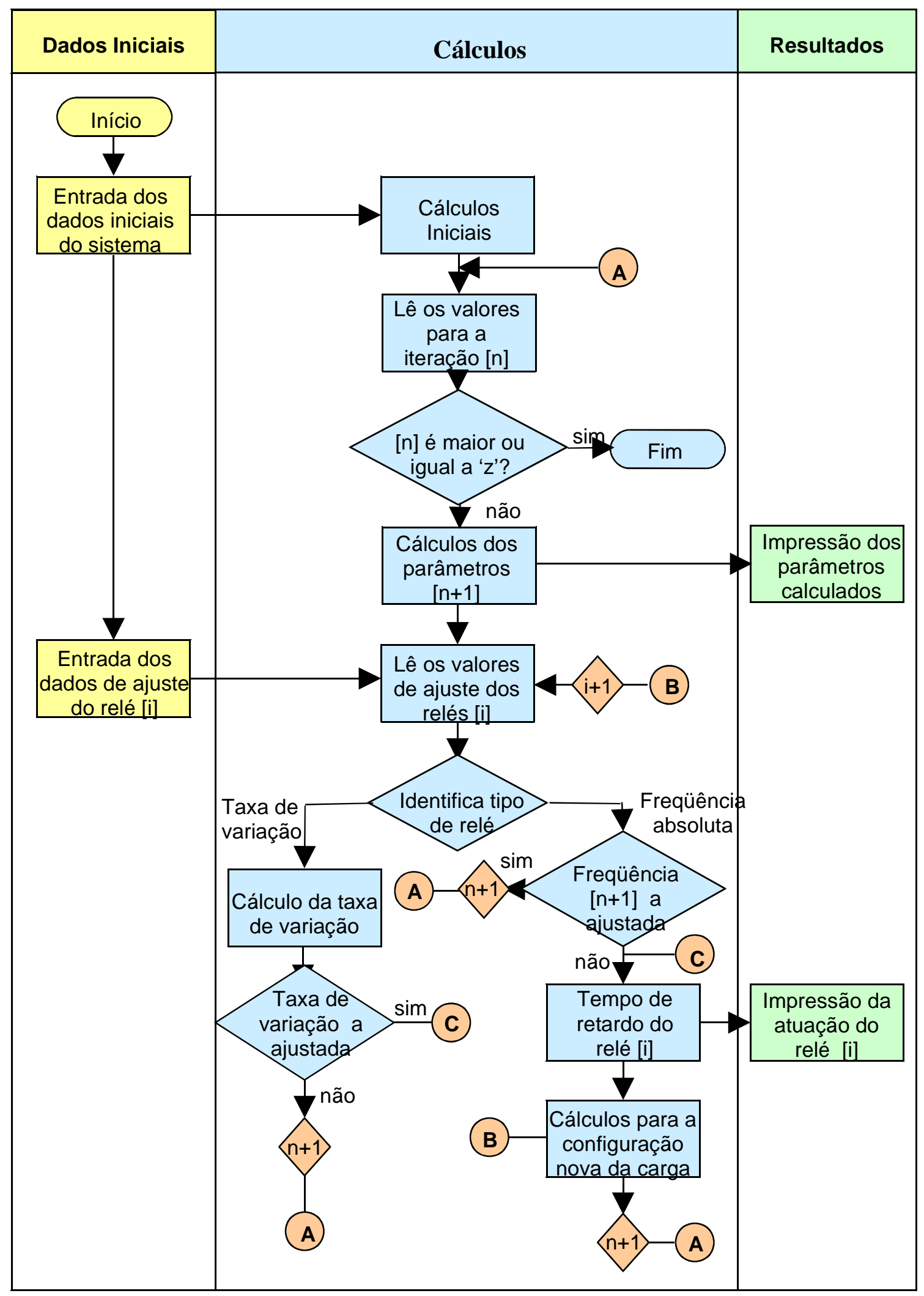

Figura 4.1 - Fluxograma do programa 
O programa foi feito utilizando técnicas de programação orientadas a objeto e utilizou-se o Delphi 5 [6] [7].

Os dados de entrada do programa são divididos em relação ao sistema e em relação a ajuste de relés.

\subsubsection{Dados de entrada do programa em relação ao sistema}

O programa deve ser alimentado, através das telas apresentadas nas figuras seguintes, com:

- $\quad$ O tempo de simulação, que é o tempo em que o programa efetuará as iterações, deverá ser informado em segundos.

- $\quad$ p passo $\Delta t$ do método de Euler Simples, que também deverá ser informado em segundos.

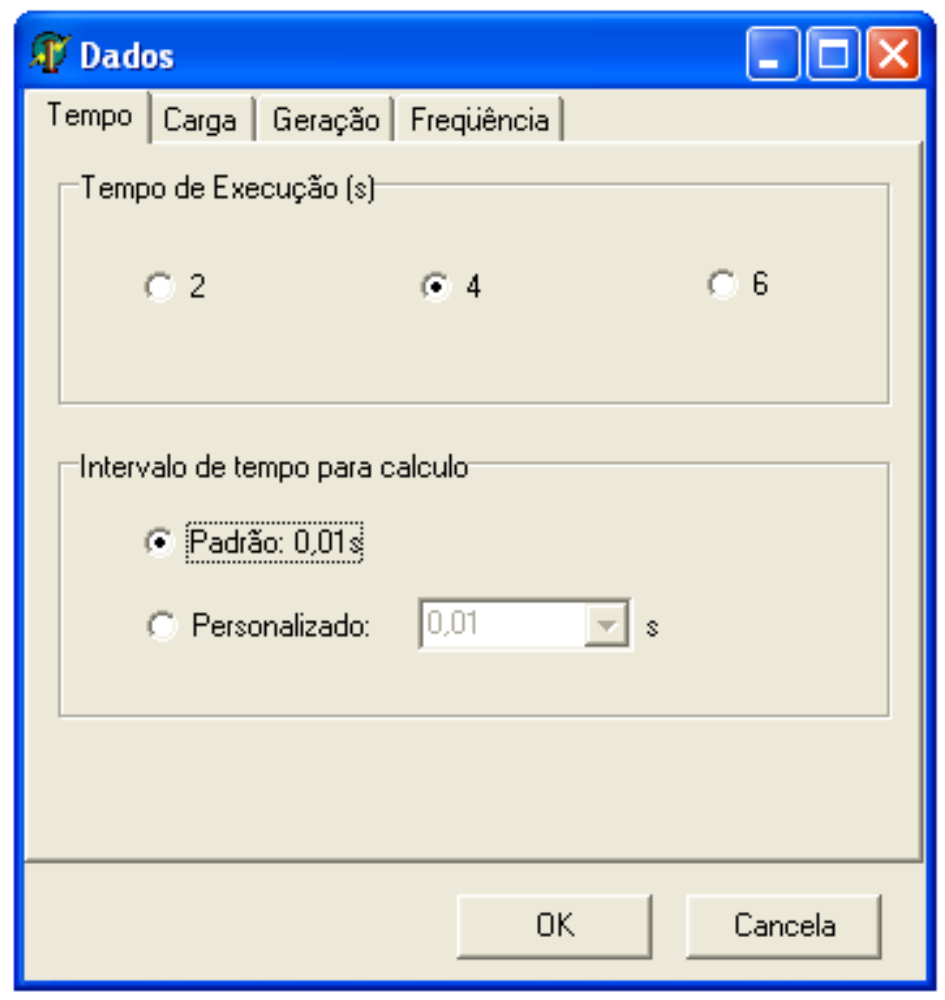

Figura 4.2 - Tela de entrada de dados (tempo) 
- A constante de amortecimento da carga.

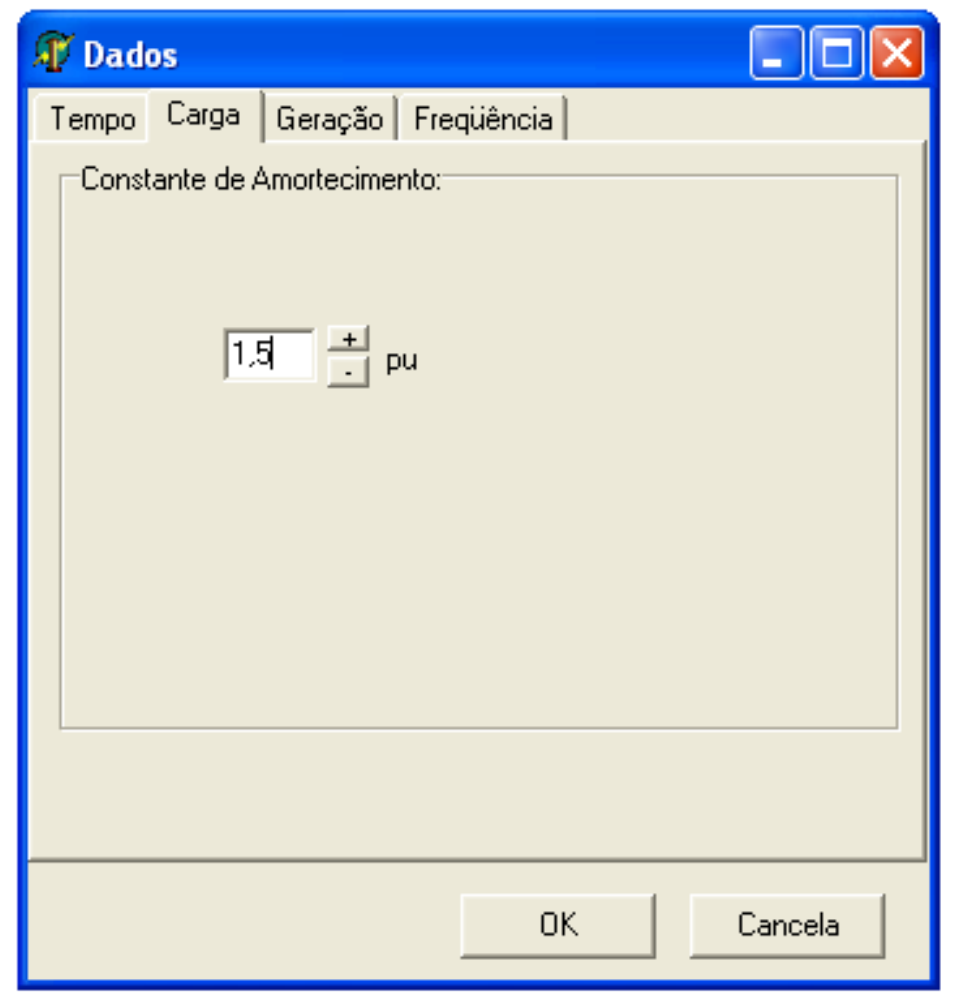

Figura 4.3 - Tela de entrada de dados (carga)

- A geração, GT, total da área estudada em MW.

- A geração, GP, perdida, também em MW.

- A constante de inércia, $\mathrm{H}$, equivalente das máquinas, colocadas na mesma base e em $\frac{M J}{M V A}$.

A base utilizada no cálculo da constante de inércia equivalente, em MVA, normalmente é de 100 MVA. 


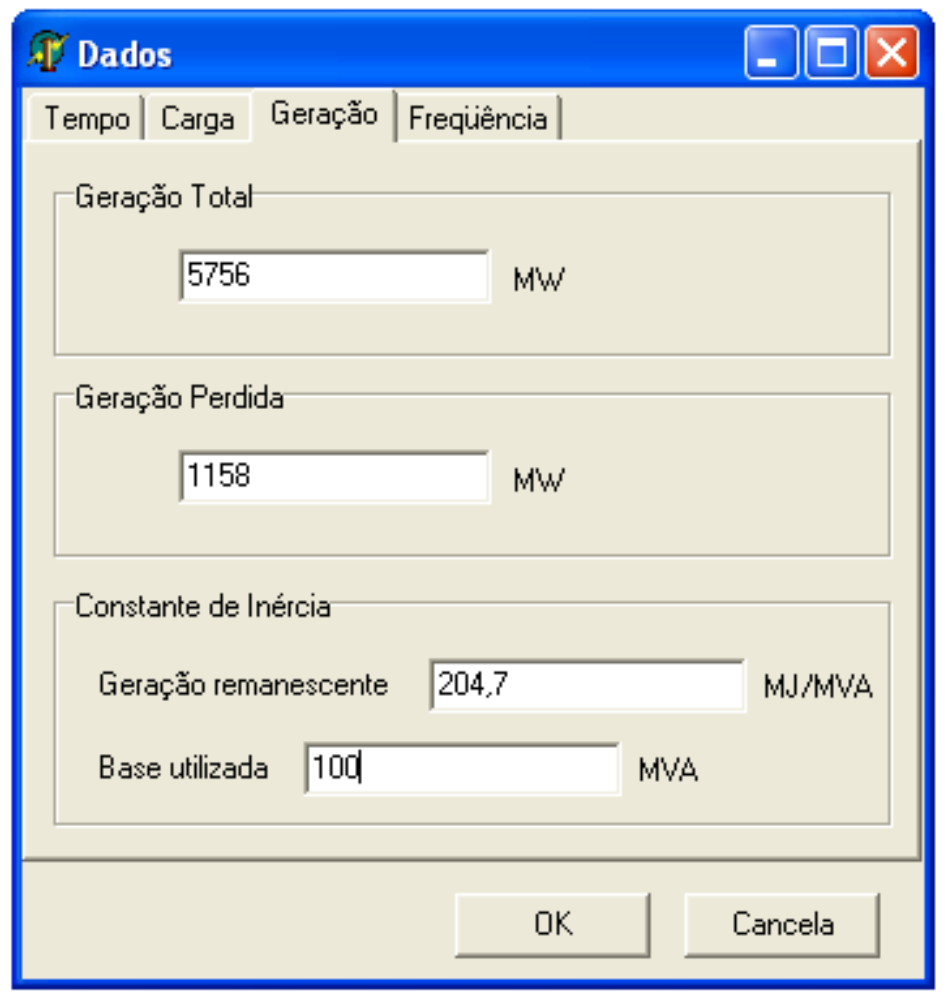

Figura 4.4 - Tela de entrada de dados (geração)

A freqüência inicial do sistema, em hertz, que geralmente é $60 \mathrm{~Hz}$.

A Fmaior $(\mathrm{Hz})$, que é a máxima frequiência permitida para a variação acima de $60 \mathrm{~Hz}$.

A Fmenor (Hz), que é mínima freqüência permitida para a variação abaixo de $60 \mathrm{~Hz}$. 


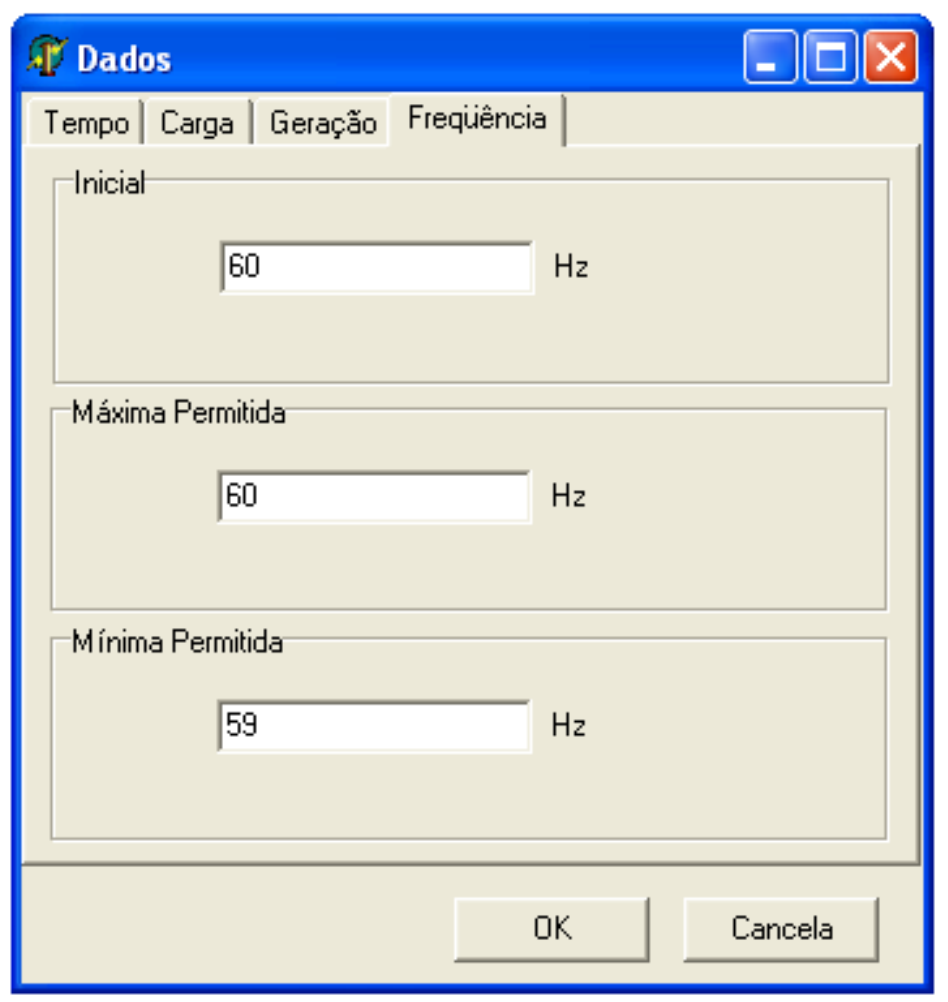

Figura 4.5 - Tela de entrada de dados (freqüência)

Os valores de freqüências permitidas para variação acima e abaixo do $60 \mathrm{~Hz}$ são dados pelos Procedimentos de Rede publicados pelo Operador Nacional do Sistema Elétrico (ONS) e são reproduzidos na tabela 4.1 [8].

Tabela 4.1 - Operação em regime de freqüência não nominal

\begin{tabular}{|c|c|c|}
\hline REQUISITOS & DESCRIÇÃO & BENEFÍCIO \\
\hline $\begin{array}{l}\text { 1. Operação em regime de } \\
\text { frequiência não nominal para } \\
\text { usinas hidrelétricas. }\end{array}$ & $\begin{array}{l}\text { (a) Operação entre } 56,5 \text { e } 66 \mathrm{~Hz} \text { sem atuação dos } \\
\text { relés de sub e sobrefrequiência instantâneos; } \\
\text { (b) Operação abaixo de } 58,5 \mathrm{~Hz} \text { por até } 20 \text { segundos; } \\
\text { (c) Operação entre } 58,5 \text { e } 63 \mathrm{~Hz} \text { sem atuação dos } \\
\text { relés de sub e sobrefrequiência temporizados; } \\
\text { (d) Operação acima de } 63 \mathrm{~Hz} \text { por até } 10 \text { segundos. }\end{array}$ & $\begin{array}{l}\text { Evitar o desligamento dos } \\
\text { geradores quando de déficit de } \\
\text { geração. }\end{array}$ \\
\hline $\begin{array}{l}\text { 1. Operação em regime de } \\
\text { freqüência não nominal para } \\
\text { usinas termelétricas. }\end{array}$ & $\begin{array}{l}\text { (a) Operação entre } 57 \text { e } 63 \mathrm{~Hz} \text { sem atuação dos relés } \\
\text { de sub e sobrefreqüência instantâneos; } \\
\text { (b) Operação abaixo de } 57,5 \mathrm{~Hz} \text { por até } 5 \text { segundos; } \\
\text { (c) Operação abaixo de } 58,5 \mathrm{~Hz} \text { por até } 10 \text { segundos; } \\
\text { (d) Operação entre } 58,5 \text { e } 61,5 \mathrm{~Hz} \text { sem atuação dos } \\
\text { relés de sub e sobrefrequiência temporizados; } \\
\text { (e) Operação acima de } 61,5 \mathrm{~Hz} \text { por até } 10 \text { segundos. }\end{array}$ & $\begin{array}{l}\text { Evitar o desligamento dos } \\
\text { geradores quando de déficit de } \\
\text { geração, antes que o esquema } \\
\text { de alívio de carga atue } \\
\text { completamente ou em } \\
\text { condições de sobrefreqüência } \\
\text { controláveis. } \\
\end{array}$ \\
\hline
\end{tabular}




\subsubsection{Dados de entrada do programa em relação aos ajustes dos relés}

O programa deve ser alimentado, para relés de freqüência absoluta:

- Freqüência absoluta, em Hz, ajustada para o relé;

- Retardo total: soma do retardo do relé com o tempo de abertura do mesmo, dado em segundos;

Porcentagem de carga rejeitada em relação à carga total do sistema estudado;

Para relés de taxa de variação:

- Taxa de variação de freqüência ajustada para o relé;

- Frequiência de supervisão, em Hz;

- Freqüência de corte, em Hz.

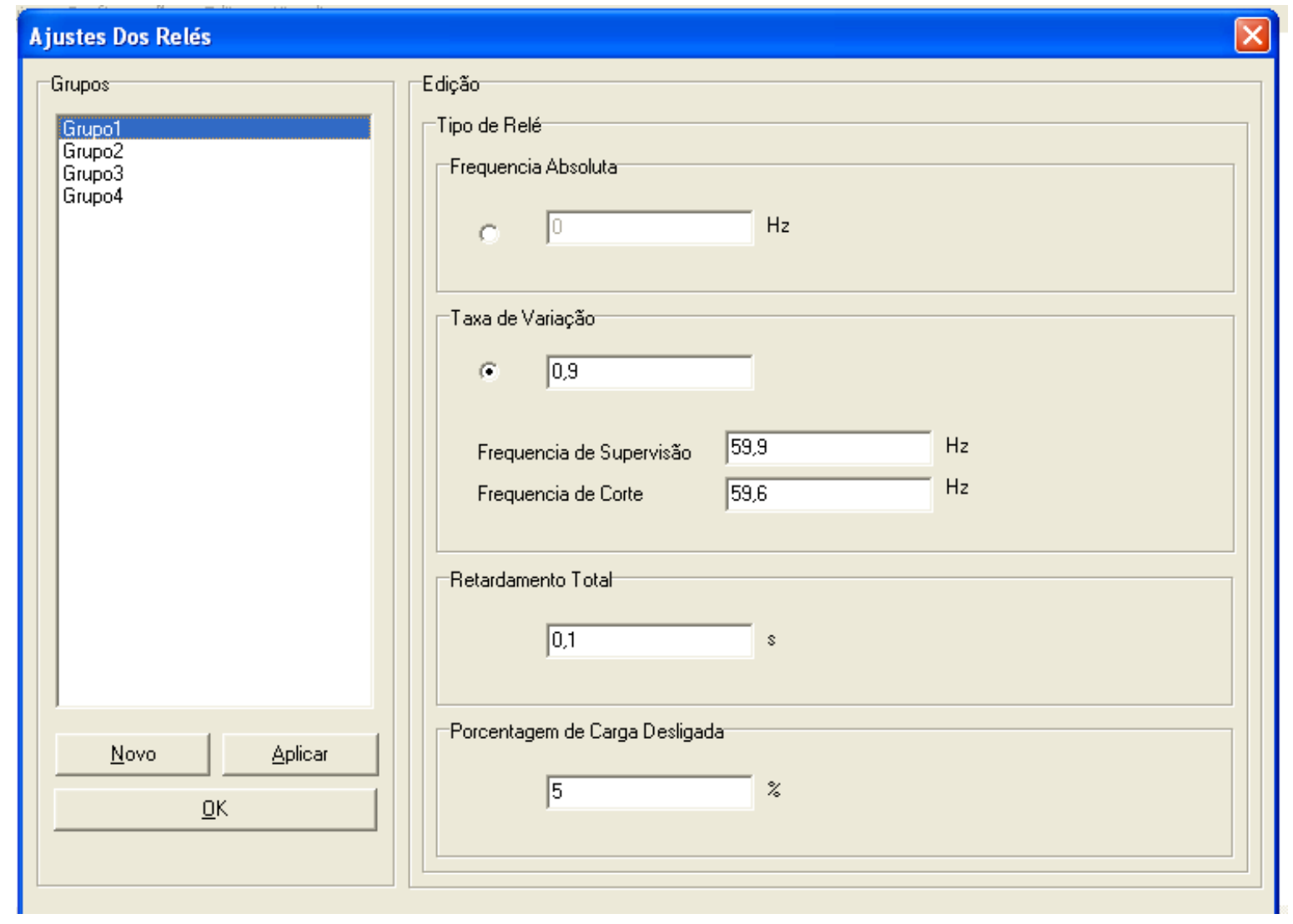

Figura 4.6 - Tela de entrada de dados de ajuste dos grupos de rejeição

A taxa de variação do relé deve ser ajustada através das frequiências de corte e freqüência de supervisão. O programa comparará a taxa de variação ajustada de acordo com a fórmula: 


$$
\mathrm{TX}=\left(\frac{F W-F[n+1]}{T E M x-T E M P O[n+1]}\right)
$$

Em que:

TX é a taxa de variação calculada pelo programa e que será a comparada com a ajustada;

FW é a primeira frequiência calculada que ficou abaixo da freqüência de supervisão

$\mathrm{F}[\mathrm{n}+1]$ é a primeira freqüência calculada que ficou abaixo da freqüência de corte;

TEMx é o instante em que ocorre a freqüência $\mathrm{FW}$;

TEMPO[n+1] é o instante em que ocorre a freqüência $F[n+1]$.

\subsubsection{Os dados de saída do programa}

Os resultados apresentados pelo problema são mostrados em uma tabela onde, para cada iteração feita durante o tempo de execução do problema, têm-se: O tempo decorrido desde o início, a freqüência, a taxa média, $D F / D T$, o conjugado da geração, o conjugado da carga, o tempo acumulado em que a freqüência ficou abaixo da freqüência mínima permitida, Fmenor, e o tempo acumulado em que a freqüência ficou acima frequiência máxima permitida, Fmaior.

Sempre que ocorre uma rejeição de carga, aparece indicado na tabela o instante em que ocorreu tal rejeição.

Quando houver algum grupo cujo relé seja o de taxa de variação de freqüência, deverá aparecer na tabela geral de resultados a taxa calculada, para ser comparada com a taxa ajustada. 
Arquivo Configurações Editar Visualizar

\begin{tabular}{|c|c|c|c|c|c|c|c|c|c|}
\hline Tempo[s] & Freq $(\mathrm{Hz}]$ & $\operatorname{Taxa}(\mathrm{Hz} / \mathrm{s}]$ & TGer(pu) & TCarga(pu) & Tempo Acima(s) & Tempo Abaixo(s) & Disparo do Relé & Taxa calculada & \\
\hline 0,02 & $59,9660886424^{-}$ & $-1,69401802505$ & $=1,00056550891$ & 1,2514948141 & 0 & 0 & 0 & 0 & \\
\hline 0,03 & 59,9491794150 & $-1,69092273375$ & 1,00084772778 & 31,2513183535 & 0 & 0 & 0 & 0 & \\
\hline 0,04 & 59,93230109650 & $(-1,68783185714$ & 41,00112958959 & 91,2511421906 & 0 & 0 & 0 & 0 & \\
\hline 0,07 & 59,8818511522 & $5 \cdot 1,67858569297$ & 1,00197303265 & 51,2506154852 & 0 & 0 & 0 & 0 & \\
\hline 0,08 & 59,8650960277 & $-1,67551245258$ & $=1,00225346623$ & 31,2504405099 & 0 & 0 & 0 & 0 & \\
\hline 0,09 & 59,8483715915 & $-1,6724436155 \mathrm{E}$ & 1,00253354275 & 51,2502658307 & 0 & 0 & 0 & 0 & \\
\hline 0,13 & 59,78177985079 & s.1,66021225495 & $=1,00365027855$ & 51,2495700678 & 0 & 0 & 0 & 0 & \\
\hline 0,14 & $59,7652081967 \varsigma$ & $\{-1,65716540003$ & $=1,00392856998$ & 91,2493968639 & 10 & 0 & 0 & 0 & \\
\hline 0.15 & 59,7486669674 & $-1,65412293450$ & {$[1,00420650443$} & 31.2492239540 & 0 & 0 & 0 & 0 & \\
\hline 0,16 & 59,73215611888 & $\{-1,65108485601$ & 11,00448408191 & 1,2490513378 & 0 & 0 & 0 & 0 & \\
\hline 0.17 & 59,71567560726 & f $-1,6480511621 \mathrm{E}$ & $=1,00476130245$ & 51,2488790150 & 0 & 0 & 0 & 0 & \\
\hline 0.18 & 59,6992253887 & $-1,64502185057$ & 1,00503816606 & 61,2487069853 & 0 & 0 & 0 & 0 & \\
\hline 0,19 & 59,68280541956 & $6-1,64199691884$ & 41,00531467276 & 1,2485352482 & & 0 & 0 & 0 & $\nabla$ \\
\hline 1 & & & & & & & & & 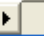 \\
\hline
\end{tabular}

Figura 4.7 - Tela de saída dos dados 


\section{EXEMPLOS DA APLICAÇÃO DO PROGRAMA NA RESOLUÇÃO DE PROBLEMAS DE MANTER O EQUILÍBRIO CARGA-GERAÇÃO APÓS PERDA DE GERAÇÃO}

\subsection{INTRODUÇÃO}

Neste capítulo serão apresentados dois exemplos de um sistema de alívio de carga.

Por meio destes exemplos será mostrada a consistência do programa.

O primeiro é um caso virtual usando o programa Varf-5, o qual também é usado para implementar sistemas de alívio de carga [3].

O Segundo exemplo é real e é o ERAC do Sistema Isolado do Amapá, que é de responsabilidade da Eletronorte. Os resultados obtidos no programa vão ser comparados ao ERAC atual, que foi desenvolvido através das simulações feitas no programa Anatem, do CEPEL, e de dados recolhidos em campo [1].

\subsection{EXEMPLO DO VARF-5}

Este exemplo foi tirado da uma Nota Técnica da Eletronorte e seus resultados foram obtidos pelo programa Varf-5 [3], implementado a partir do Varf-4, desenvolvido, em Fortran, pelo Engenheiro Heinrich Parfijanowitsch [9], da Ligth, e apresentado no III Seminário Nacional de Produção e Transmissão de Energia Elétrica.

O Varf-5 é o aplicativo computacional no qual foi baseado o programa desenvolvido neste projeto. Ele também não leva em conta os dados elétricos do sistema e os dados dos reguladores.

\subsubsection{Dados de entrada}

Os dados de entrada são apresentados na tabela 5.1. 
Tabela 5.1 - Dados de entrada para o exemplo proposto para comparação com o programa Varf-5

\begin{tabular}{|l|c|}
\hline \multicolumn{2}{|c|}{ DADOS DE ENTRADA } \\
\hline Freqüência inicial & $60,0 \mathrm{~Hz}$ \\
\hline Constante de inércia do sistema & $204,7 \mathrm{MJ} / \mathrm{MVA}$ \\
\hline Base utilizada nos cálculos da constante de inércia & $100,0 \mathrm{MVA}$ \\
\hline Constante de amortecimento da carga & 1,5 \\
\hline Demanda inicial da área & $5756,0 \mathrm{MW}$ \\
\hline Geração ou interligação perdida & $1158,0 \mathrm{MW}$ \\
\hline Intervalo de tempo dos cálculos & $0,01 \mathrm{~s}$ \\
\hline Tempo de execução & $4,0 \mathrm{~s}$ \\
\hline
\end{tabular}

\subsubsection{Dados de ajuste do relé}

São ajustados nove grupos de rejeição, sendo que os dois primeiros são implementados com relés de taxa de variação de freqüência e os outros por frequiência absoluta.

Os dados de ajustes para cada grupo estão relacionados na tabela 5.2. 
Tabela 5.2 - Dados de ajuste dos relés para o exemplo proposto para comparação com o programa Varf-5

\begin{tabular}{|c|c|c|c|c|c|c|c|}
\hline \multicolumn{7}{|c|}{ AJUSTES DOS RELÉS DE FREQÜÊNCIA } \\
\hline Tipo & Grupo & $\begin{array}{c}\text { Freqüência } \\
\text { Absoluta } \\
(\mathbf{H z})\end{array}$ & $\begin{array}{c}\text { Retardo } \\
(\mathbf{s})\end{array}$ & $\begin{array}{c}\text { Carga } \\
\text { Rejeitada } \\
(\%)\end{array}$ & $\begin{array}{c}\text { Taxa de } \\
\text { Variação }\end{array}$ & $\begin{array}{c}\text { Freqüência } \\
\text { Supervisão } \\
(\mathbf{H z})\end{array}$ & $\begin{array}{c}\text { Freqüência } \\
\text { Corte (Hz) }\end{array}$ \\
\hline $\begin{array}{c}\text { Taxa de } \\
\text { variação }\end{array}$ & 1 & - & 0,100 & 5,00 & 0,90 & 59,90 & 59,60 \\
\hline $\begin{array}{c}\text { Taxa de } \\
\text { variação }\end{array}$ & 2 & - & 0,100 & 5,00 & 0,40 & 59,90 & 59,20 \\
\hline $\begin{array}{c}\text { Freqüência } \\
\text { Absoluta }\end{array}$ & 3 & 58,80 & 0,100 & 5,00 & - & - & - \\
\hline $\begin{array}{c}\text { Freqüência } \\
\text { Absoluta }\end{array}$ & 4 & 58,40 & 0,100 & 6,00 & - & - & - \\
\hline $\begin{array}{c}\text { Freqüência } \\
\text { Absoluta }\end{array}$ & 5 & 58,00 & 0,100 & 7,20 & - & - & - \\
\hline $\begin{array}{c}\text { Freqüência } \\
\text { Absoluta }\end{array}$ & 6 & 57,60 & 0,100 & 7,20 & - & - & - \\
\hline $\begin{array}{c}\text { Freqüência } \\
\text { Absoluta }\end{array}$ & 7 & 57,20 & 0,100 & 5,60 & - & - & - \\
\hline $\begin{array}{c}\text { Freqüência } \\
\text { Absoluta }\end{array}$ & 8 & 56,80 & 0,100 & 5,60 & - & - & - \\
\hline $\begin{array}{c}\text { Freqüência } \\
\text { Absoluta }\end{array}$ & 9 & 56,40 & 0,100 & 6,00 & - & - & - \\
\hline
\end{tabular}

\subsubsection{Resultados obtidos no programa Varf-5}

Os resultados fornecidos pelo programa Varf -5 são apresentados no Apêndice C.

Apesar do programa efetuar cálculos a cada 0.01 segundos, os resultados exibidos no Apêndice C são a cada 0.02 segundos, com exceção dos instantes em que há desligamento de carga.

Outros resultados exibidos são:

A taxa de variação ajustada e a calculada pelo programa no instante em que há desligamento de carga; a freqüência, o conjugado da carga, o conjugado da geração, a área acumulada abaixo de $59 \mathrm{~Hz}$, a área acumulada entre 59 e $60 \mathrm{~Hz}$ e a área acumulada acima de $60 \mathrm{~Hz}$.

Um resumo dos resultados obtidos é dado na tabela 5.3.

Tabela 5.3 - Resumo dos resultados obtidos da simulação no programa Varf-5 


\begin{tabular}{|c|c|c|c|c|c|c|c|c|}
\hline $\begin{array}{c}\text { Grupo } \\
\text { desligado }\end{array}$ & Instante & Freqüência & $\begin{array}{c}\text { Taxa de } \\
\text { variação }\end{array}$ & $\begin{array}{c}\text { Transitório } \\
\text { da Carga }\end{array}$ & $\begin{array}{c}\text { Transitório } \\
\mathbf{d a} \\
\text { Geração }\end{array}$ & $\begin{array}{c}\text { Área } \\
\text { Abaixo } \\
\mathbf{5 9 H z}\end{array}$ & $\begin{array}{c}\text { Área entre } \\
\mathbf{5 9} \mathbf{e} \mathbf{6 0} \mathbf{H z}\end{array}$ & $\begin{array}{c}\text { Taxa de } \\
\text { variação } \\
\text { calculada }\end{array}$ \\
\hline 1 & 0,350 & 59,429 & $-1,567$ & 1,246 & 1,010 & 0,0 & 0,104 & 1,6383 \\
\hline 2 & 0,660 & 59,084 & $-1,077$ & 1,015 & 1,180 & 0,0 & 0,337 & 1,3770 \\
\hline 3 & 1,210 & 58,737 & $-0,600$ & 1,021 & 1,114 & 0,058 & 0,939 & - \\
\hline 4 & 3,390 & 58,386 & $-0,133$ & 1,027 & 1,048 & 1,039 & 4,101 & - \\
\hline
\end{tabular}

\subsubsection{Resultados obtidos no programa elaborado}

O programa foi alimentado conforme os dados fornecidos acima, e gerou como resultado, os exibidos na tabela 5.4.

Tabela 5.4 - Resumo dos resultados obtidos da simulação do programa proposto

\begin{tabular}{|c|c|c|c|c|c|c|c|c|}
\hline $\begin{array}{c}\text { Tempo } \\
(\mathbf{s})\end{array}$ & $\begin{array}{c}\text { Freqüência } \\
\mathbf{( H z )}\end{array}$ & $\begin{array}{c}\text { Taxa } \\
\mathbf{( H z / s )}\end{array}$ & $\begin{array}{c}\text { T. Ger } \\
(\mathbf{p u})\end{array}$ & $\begin{array}{c}\text { T. Carga } \\
\mathbf{( p u )}\end{array}$ & $\begin{array}{c}\text { Tempo } \\
\text { acima (s) }\end{array}$ & $\begin{array}{c}\text { Tempo } \\
\text { abaixo (s) }\end{array}$ & $\begin{array}{c}\text { Ocorre } \\
\text { disparo } \\
\text { do relé }\end{array}$ & $\begin{array}{c}\text { Taxa de } \\
\text { variação } \\
\text { calculada }\end{array}$ \\
\hline 0,000 & 60,0000 & 0,0000 & 1,0000 & & 0 & 0,00 & - & - \\
\hline 0,200 & 59,6640 & $-1,6389$ & 1,0055 & 1,2483 & 0 & 0,00 & - & - \\
\hline 0,350 & 59,4241 & $-1,5900$ & 1,0096 & 1,1678 & 0 & 0,00 & sim & 1,6512 \\
\hline 0,400 & 59,3710 & $-1,1380$ & 1,0105 & 1,1673 & 0 & 0,00 & - & - \\
\hline 0,600 & 59,1634 & $-1,2030$ & 1,0141 & 1,1652 & 0 & 0,00 & - & - \\
\hline 0,670 & 59,0975 & $-1,0074$ & 1,0154 & 1,0917 & 0 & 0,00 & sim & 1,0447 \\
\hline 0,800 & 59,0263 & $-0,5040$ & 1,0164 & 1,0911 & 0 & 0,00 & - & - \\
\hline 1,000 & 58,9270 & $-0,4850$ & 1,0181 & 1,0901 & 0 & 0,15 & - & - \\
\hline 1,200 & 58,8320 & $-0,4680$ & 1,0198 & 1,0890 & 0 & 0,35 & - & - \\
\hline 1,370 & 58,7539 & $-0,4540$ & 1,0212 & 1,0204 & 0 & 0,52 & sim & \\
\hline 1,400 & 58,7539 & 0,0053 & 1,0210 & 1,0204 & 0 & 0,55 & - & - \\
\hline 1,600 & 58,5640 & 0,0051 & 1,0212 & 1,0204 & 0 & 0,75 & - & - \\
\hline 1,800 & 58,7559 & 0,0049 & 1,0211 & 1,0204 & 0 & 0,95 & - & - \\
\hline 2,000 & 58,7560 & 0,0047 & 1,0211 & 1,0204 & 0 & 1,15 & - & - \\
\hline 2,200 & 58,7570 & 0,0046 & 1,0210 & 1,0204 & 0 & 1,35 & - & - \\
\hline 2,400 & 58,7587 & 0,0044 & 1,0211 & 1,0205 & 0 & 1,56 & - & - \\
\hline 2,600 & 58,7590 & 0,0042 & 1,0210 & 1,0204 & 0 & 1,76 & - & - \\
\hline 2,800 & 58,7605 & 0,0041 & 1,0210 & 1,0205 & 0 & 1,96 & - & - \\
\hline 3,000 & 58,7610 & 0,0039 & 1,0210 & 1,0200 & 0 & 2,16 & - & - \\
\hline 3,200 & 58,7621 & 0,0038 & 1,0210 & 1,0200 & 0 & 2,36 & - & - \\
\hline 3,400 & 58,7629 & 0,0097 & 1,0205 & 2,5590 & 0 & 2,56 & - & - \\
\hline 3,600 & 58,7635 & 0,0035 & 1,0200 & 2,7590 & 0 & 2,76 & - & - \\
\hline 3,800 & 58,7640 & 0,0034 & 1,0205 & 2,9550 & 0 & 2,96 & - & - \\
\hline & & & & & & & & \\
\hline
\end{tabular}

\subsubsection{Comparação dos resultados}

Ao se comparar os dados, nota-se a semelhança no começo das iterações. Já a freqüência no programa desenvolvido se estabilizou mais rapidamente em relação à simulação feita no Varf - 5. Com isso, não houve a necessidade de disparo do grupo IV. 
Para mostrar essa comparação utilizou-se o gráfico abaixo.

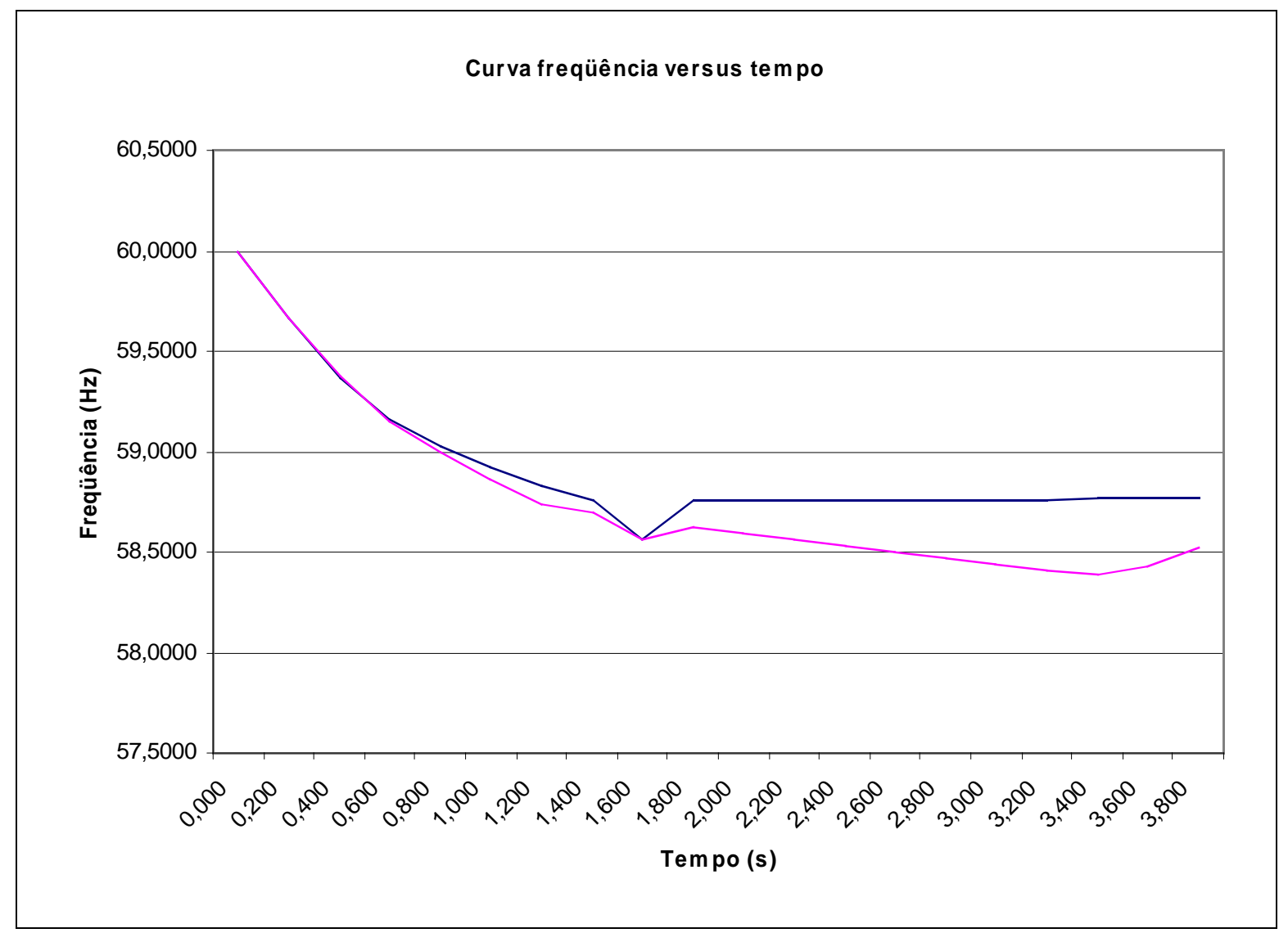

Figura 5.1 - Gráfico de comparação Varf e programa proposto

\subsection{EXEMPLO SISTEMA ISOLADO AMAPÁ}

O sistema elétrico do Amapá é um sistema isolado hidrotérmico e está dentro da área de atuação das Centrais Elétricas do Norte do Brasil (Eletronorte). 


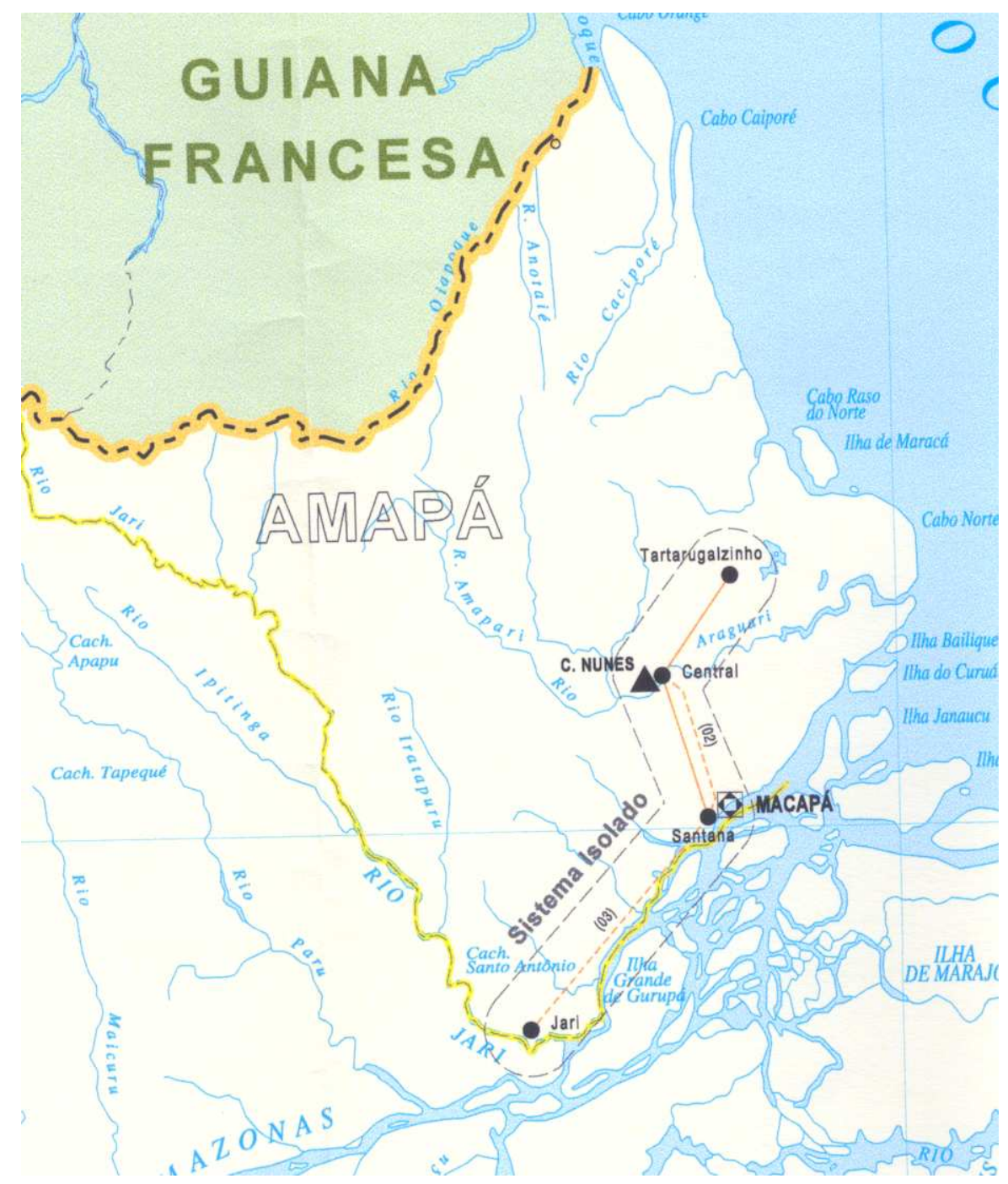

Figura 5.1 - Mapa do Amapá com a representação do sistema elétrico.

As linhas de transmissão entre as usinas Coaracy Nunes, Santana e as subestações em Macapá são apresentados no mapa exibido na figura 5.1 acima.

\subsubsection{Dados do sistema}

O sistema elétrico do Amapá atualmente é formado pela usina hidroelétrica de Coaracy Nunes, composta de três geradores com um total de aproximadamente 70 MW disponíveis, e pela usina termoelétrica Santana composta de sete unidades térmicas com um total de 110 MW disponíveis. Os parâmetros das máquinas são apresentados nas tabelas 5.4 e 5.5 . 
Tabela 5.5 - Dados das máquinas da Usina Termoelétrica Santana

\begin{tabular}{|c|c|c|c|c|c|}
\hline \multicolumn{2}{|c|}{ MÁQUINA } & UGG-01 & UGG-02 & UGG-03 & UGD-04 A 07 \\
\hline \multicolumn{2}{|c|}{ Tipo de Turbina } & LM2500 & LM2500 & LM2500 & WARTISILA \\
\hline \multicolumn{2}{|c|}{ Gerador: número de referência } & $60728 \mathrm{~A}-1 \mathrm{G}$ & $60759 \mathrm{~A}-1 \mathrm{G}$ & $60729 \mathrm{~A}-1 \mathrm{G}$ & - \\
\hline \multicolumn{2}{|c|}{ Modelo do gerador } & BDAX7-167E & BDAX7-167E & BDAX7-167E & HSG1600SR14 \\
\hline \multicolumn{2}{|c|}{ Potência aparente (kVA) } & 28291 & 26111 & 28291 & 18581 \\
\hline \multicolumn{2}{|c|}{ Fator de potência } & 0,85 & 0,90 & 0,85 & 0,85 \\
\hline \multirow{2}{*}{$\begin{array}{c}\text { Constante de } \\
\text { inércia } \\
\text { (kW.s/kVA) }\end{array}$} & $\begin{array}{c}\text { na base da } \\
\text { máquina }\end{array}$ & 1,91 & 2,07 & 1,91 & 1,4852 \\
\hline & na base 100 & 0,54 & 0,54 & 0,54 & 0,2760 \\
\hline
\end{tabular}

Tabela 5.6 - Dados das máquinas da Usina Hidroelétrica Coaracy Nunes

\begin{tabular}{|c|c|c|c|c|}
\hline \multicolumn{2}{|c|}{ MÁQUINA } & UGH-01 & UGH-02 & UGH-03 \\
\hline \multicolumn{2}{|c|}{ Tipo de Turbina } & KAPLAN(HITACHI) & KAPLAN(HITACHI) & KAPLAN(HITACHI) \\
\hline \multicolumn{2}{|c|}{$\begin{array}{c}\text { Gerador: número de } \\
\text { referência }\end{array}$} & $511468-1$ & $511468-2$ & SP97110156401 \\
\hline \multicolumn{2}{|c|}{ Modelo do gerador } & - & - & 1DH7139-3WF24-Z \\
\hline \multicolumn{2}{|c|}{ Potência aparente (kVA) } & 28291 & 26111 & 28291 \\
\hline \multicolumn{2}{|c|}{ Fator de potência } & 0,85 & 0,85 & 0,95 \\
\hline \multirow{2}{*}{$\begin{array}{c}\text { Constante de } \\
\text { inércia } \\
\text { (kW.s/kVA) }\end{array}$} & $\begin{array}{c}\text { Na base da } \\
\text { máquina }\end{array}$ & 0,429006 & 0,429006 & 0,4943116 \\
\hline & Na base 100 & 1,8652433 & 1,8652433 & 1,6259180 \\
\hline
\end{tabular}


A maior parte da carga (96,3\%) do sistema Amapá está distribuída radialmente pelas subestações Santa Rita (em fevereiro de 2006, que substituirá a SE Macapá I), Macapá II, Equatorial, Santana e Portuária. O diagrama unifilar é apresentado na figura 5.2 abaixo.

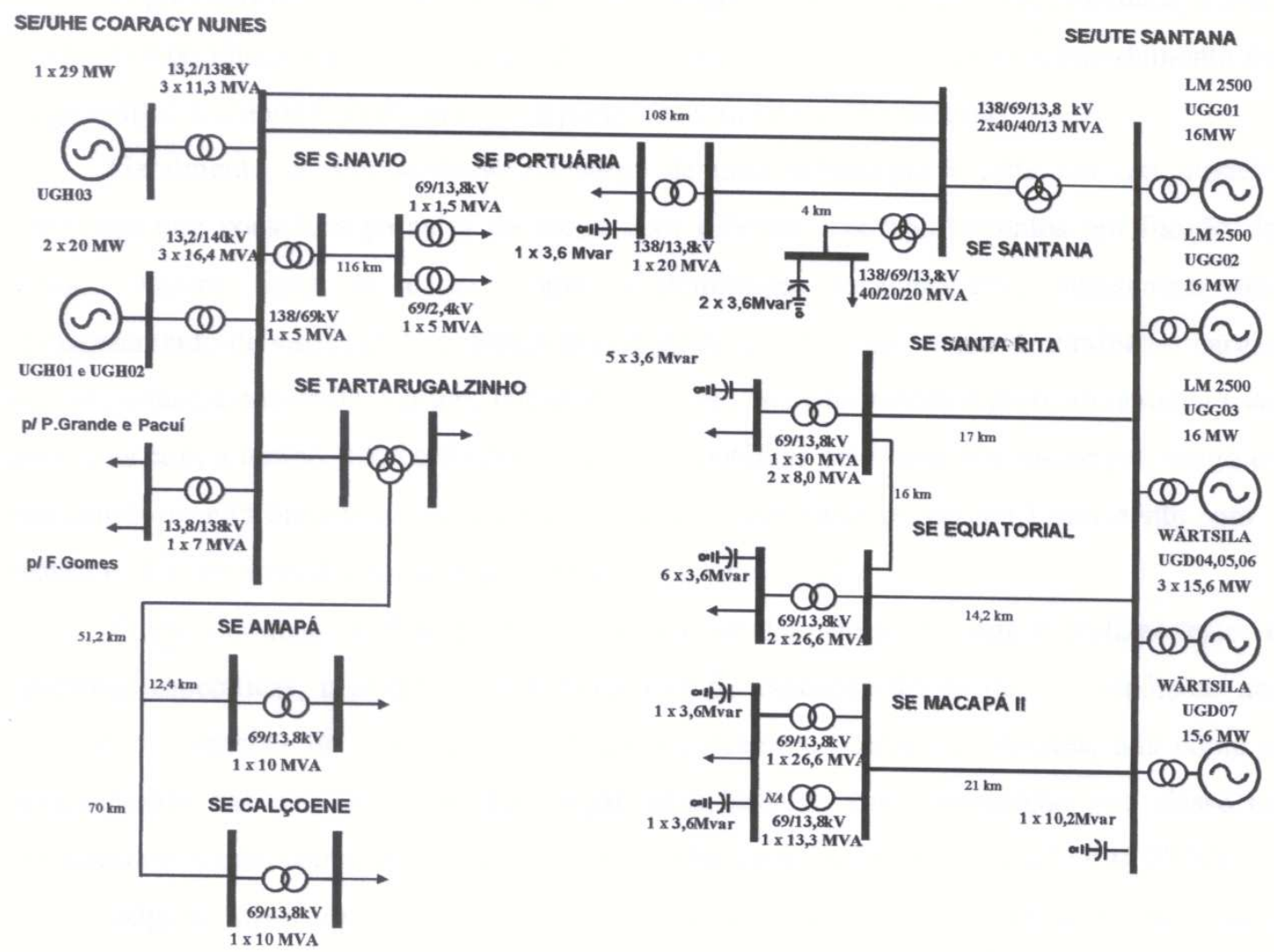

Figura 5.2 - Diagrama Unifilar do sistema elétrico do Amapá

Para as simulações serem mais precisas, no sistema elétrico do Amapá, muitos parâmetros são analisados. Por isso, levam-se em consideração os períodos de carga leves, médias e pesadas, e também as épocas de baixa e alta hidraulicidades.

Será usado no exemplo o período de carga pesada na época de alta hidraulicidade. O despacho de potência nesta configuração é dado pela tabela 5.6 abaixo.

Tabela 5.7 - Dados de entrada de geração para o exemplo 2

\begin{tabular}{|c|c|c|c|c|c|c|}
\hline \multicolumn{7}{|c|}{ DESPACHO TOTAL DE POTÊNCIA } \\
\hline \multicolumn{3}{|c|}{ Hidrelétrica } & \multicolumn{4}{c|}{ Termoelétrica } \\
\hline UGH - 01 & UGH - 02 & UGH - 03 & UGG - 01 & UGG - 02 & UGG - 03 & UGD - 04 a 07 \\
\hline $20 \mathrm{MW}$ & $27 \mathrm{MW}$ & - & $6 \mathrm{MW}$ & - & - & $4 \times 15 \mathrm{MW}$ \\
\hline
\end{tabular}

A configuração da carga no sistema foi considerada: Parte ativa, 70\% de impedância constante e $20 \%$ de potência constante, e parte reativa com $100 \%$ a impedância constante. 


\subsubsection{Dados de ajuste dos relés}

O ERAC do sistema elétrico do Amapá é formado apenas por relés de frequiência absoluta.

A configuração desse ERAC é dada na tabela 5.8 abaixo, e esses serão também os dados ajustados para rejeição dos grupos no programa.

O tempo de abertura (tabela 5.9) será a soma da temporização (tabela 5.8), e do tempo de retardo dos disjuntores, ou só o retardo dos disjuntores nos ajustes instantâneos.

Tabela 5.8 - Configuração de desligamento de carga do ERAC do Sistema Amapá

\begin{tabular}{|c|c|c|c|c|c|}
\hline \multicolumn{2}{|c|}{ ERAC DO AMAPÁ } \\
\hline \multirow{3}{*}{ Grupo } & \multirow{2}{*}{ Subestação } & \multicolumn{2}{|c|}{ Ajustes } & \multicolumn{2}{c|}{ Carga selecionada } \\
\cline { 3 - 6 } & & FREQÜENCIA & Temporização & Carga Ativa & Carga Ativa \\
$(\mathbf{H z})$ & $(\mathbf{\%})$ & 13,92 & $(\mathbf{M W})$ \\
\hline 1 & Equatorial & 58,5 & instantânea & 8,48 & $1 \times 3,6$ \\
\hline 2 & Macapá II & 58,5 & 0,40 & 5,44 & $1 \times 7,2$ \\
\hline 3 & Santana & 58,0 & 0,30 & 5,06 & $1 \times 1,8$ \\
\hline 4 & Macapá I & 57,2 & instantânea & 9,62 & $1 \times 5,4$ \\
\hline 5 & Macapá I & 57,2 & 1,3 & & \\
\hline
\end{tabular}

Tabela 5.9 - Tempo total para abertura dos disjuntores

\begin{tabular}{|c|c|c|c|}
\hline \multicolumn{3}{|c|}{ DISJUNTORES 13,8 KV } \\
\hline \multirow{2}{*}{ Subestação } & $\begin{array}{c}\text { Tempo de Abertura } \\
(\mathbf{s})\end{array}$ & Função Subfreqüência (s) & $\begin{array}{c}\text { Tempo total } \\
\text { (s) }\end{array}$ \\
\hline Equatorial & 0,048 & 0,040 & 0,088 \\
\hline Macapá II & 0,080 & 0,060 & 0,140 \\
\hline Santana & 0,050 & 0,040 & 0,090 \\
\hline Macapá I & 0,110 & 0,050 & 0,160 \\
\hline Macapá I & 0,050 & 0,040 & 0,090 \\
\hline
\end{tabular}

\subsubsection{Dados obtidos no programa elaborado}

Serão simulados cinco casos diferentes de perda de geração. Esses dados são apresentados na tabela 5.10 abaixo.

Tabela 5.10 - Perdas de geração que serão simuladas

\begin{tabular}{|c|c|c|c|}
\hline SITUAÇÃO & $\begin{array}{l}\text { UNIDADE GERADORA } \\
\text { PERDIDA }\end{array}$ & $\begin{array}{c}\text { GERAÇÃO PERDIDA } \\
\text { (MW) }\end{array}$ & $\begin{array}{c}\text { GERAÇÃO PERDIDA } \\
\text { SOBRE GERAÇÃO }\end{array}$ \\
\hline 1 & UGH03 & 27,00 & 23,85 \\
\hline 2 & $1 \mathrm{UGH}$ & 20,00 & 17,67 \\
\hline 3 & $2 \mathrm{UGH}$ & 47,00 & 41,52 \\
\hline
\end{tabular}




\begin{tabular}{|c|c|c|c|}
\hline 4 & 1 UGD & 15,00 & 13,25 \\
\hline 5 & 3 UGD & 45,00 & 39,75 \\
\hline 6 & 1 UGG & 6,00 & 5,30 \\
\hline
\end{tabular}

\subsubsection{Comparação dos dados com o ERAC atual para o Sistema Isolado do Amapá}

Os casos simulados com o ERAC proposto no programa Anatem forneceram como resultados os apresentados na tabela 5.11 abaixo.

Tabela 5.11 - Resultados obtidos no Anatem

\begin{tabular}{|c|c|c|c|}
\hline SITUAÇ̃̃o & $\begin{array}{c}\text { TAXA } \\
(\mathbf{d f} / \mathbf{d t})\end{array}$ & $\begin{array}{c}\text { FREQÜÊNCIA } \\
\text { MÍNIMA }\end{array}$ & GRUPOS ATUADOS \\
\hline 1 & 2,65 & 58,37 & 1 \\
\hline 2 & 2,00 & 58,50 & 1 \\
\hline 3 & 6,92 & 57,42 & $1,2 \mathrm{e} 3$ \\
\hline 4 & 1,02 & 58,81 & - \\
\hline 5 & 3,53 & 57,12 & a 4 \\
\hline 6 & 0,55 & 59,49 & - \\
\hline
\end{tabular}

Fazendo a simulação do ERAC no programa proposto, utilizando como dados a tabela abaixo.

Tabela 5.12 - Dados de entrada

\begin{tabular}{|c|c|c|}
\hline SITUAÇÃO & $\begin{array}{c}\text { GERAÇÃO PERDIDA } \\
\text { (MW) }\end{array}$ & $\begin{array}{c}\text { CONTANTE DE INERCIA EQUIVALENTE } \\
\text { DA GERAÇÃO RESTANTE (pu base 100MW) }\end{array}$ \\
\hline 1 & 27 & 0,75 \\
\hline 2 & 20 & 1,05 \\
\hline 3 & 47 & 0,54 \\
\hline 4 & 15 & 1,25 \\
\hline 5 & 45 & 0,54 \\
\hline 6 & 6 & 1,86 \\
\hline
\end{tabular}

Os resultados obtidos estão resumidos na tabela abaixo.

Tabela 5.13 - Resultados obtidos no programa proposto

\begin{tabular}{|c|c|c|}
\hline SITUAÇÃO & $\begin{array}{c}\text { FREQÜÊNCIA } \\
\text { MÍNIMA }\end{array}$ & GRUPOS ATUADOS \\
\hline 1 & 58,07 & $1 \mathrm{e} 2$ \\
\hline 2 & 58,13 & $1 \mathrm{e} 2$ \\
\hline 3 & 57,1 & $1 \mathrm{a} 3$ \\
\hline 4 & 58,81 & $1 \mathrm{e} 2$ \\
\hline
\end{tabular}




\begin{tabular}{|c|c|c|}
\hline 5 & 57,08 & 1 a 4 \\
\hline 6 & 58,9 & - \\
\hline
\end{tabular}

Analisando-se os resultados, nota-se, em todas as simulações, que mais grupos foram desligados no programa proposto em relação ao fornecido pelo Anatem. Isto se deve, principalmente, pelo fato de o Anatem levar em consideração nos seus cálculos os modelos dos reguladores. 


\section{CONCLUSÕES E SUGESTÕES PARA TRABALHOS FUTUROS}

Por meio das simulações feitas nos exemplos do capítulo 5, nota-se que os dados do programa desenvolvido neste projeto são compatíveis com os esperados teoricamente.

Existe o decréscimo da freqüência, quando da perda de geração, e essa queda é atenuada quando há desligamento de blocos de carga.

Os exemplos apresentados, também, mostram que os resultados são compatíveis com os informados nos programas que forneceram os dados para a comparação.

Como o programa desenvolvido não leva em consideração os modelos dos reguladores das máquinas, seus dados serão mais precisos quando o sistema está sem reserva girante.

Pode-se afirmar que este programa será uma ferramenta útil na elaboração de ERACs, uma vez que fornecerá os dados iniciais ou o "pior caso" para a análise e para os ajustes posteriores em programas mais elaborados.

É proposta, para trabalhos futuros, a implementação, no código do programa, de métodos que permitam a entrada dos modelos dos reguladores das máquinas. Isso aumentaria sua eficiência e utilidade. Entretanto, como já existem programas como o Anatem, que já trabalha com modelos de reguladores e estes são consideravelmente complexos, pode ser interessante que o programa desenvolvido neste projeto não use tais modelos, visto que diminuirá o esforço aplicado em simulações mais precisas, a fim de se obter os ajustes necessários para casos mais pessimistas, na implementação de um ERAC, sendo de maior utilidade como uma ferramenta auxiliar para programas mais elaborados.

Melhorias na parte de visualização e implementação dos resultados poderão ser feitas, à medida que se desenvolvem mais componentes para a linguagem de programação Delphi, que é a linguagem utilizada na elaboração deste programa. 


\section{REFÊRENCIAS BIBLIOGRÁFICAS}

[1] TEIXEIRA, RICARDO MARCELO. Análise e Aperfeiçoamento do Esquema de Controle de Emergências do Tipo Esquema Regional de Alívio de Carga por

SUBFREQÜÊNCIA. Dissertação de Mestrado, Departamento de Engenharia Elétrica UnB, 2003.

[2] DALZIEL, C. F., STEINBACK E. W.. Underfrequency Protection of Power Systems for System Relief. IEEE Paper 59806, 1959.

[3] SOUSA, EDUARDO CASTROVIEJO. Programa Varf-V - Estudos de Esquemas de Conservação de Carga - Manual de Utilização. Nota Técnica Eletronorte 00SE-03/90, 1990.

[4] CAMARGO, I.M.T.. Estabilidade de Sistemas de Potência. Material Didático UnB/Eletrobrás/Prodespo, 2000.

[5] BERDY, J.. Load Shedding - Aplication Guide. Publicação interna da General Eletric CO.

[6] CARVALHO, FAIÇAL FARHAT DE. Delphi 6: Programação voltada a objeto, Editora Érica, 2001.

[7] SONNINO, BRUNO. Desenvolvendo Aplicação com Delphi 6, Makron Books, 2001.

[8] ONS. Procedimentos de Rede-Modulo 3: Aceso aos Sistemas de Transmissão. Rio de Janeiro, abril de 2001.

[9] PARFIJANOWITSCH, H.. Aplicação de Computadores Digitais em Estudos de Esquemas de Conservação de Carga - Apresentação no III Seminário Nacional de Produção e Transmissão de Energia Elétrica. 
ANEXOS 


\section{ANEXO I - ALGORITMO DO PROGRAMA}

\section{Programa: CalcSub}

Declare variáveis: TE, FI, DELT, H, cc, BMVA, GT, GP, Fmaior, Fmenor, GR, SBC, CONST, n, TOD, menorF, TEMx, TEMy, maiorF, FW; reais.

$\mathrm{u}, \mathrm{i}, \mathrm{j}, \mathrm{k}, \mathrm{s}, \mathrm{z}$; inteiras.

FR[i], TR[i], PR[i], Z[i], TV[i], FX[i], FY[i], INTO[i], TX[i]; vetor de reais

onde $\mathrm{i}: 1 \rightarrow \mathrm{u}$.

reais onde $\mathrm{n}: 0 \rightarrow \mathrm{z}$.

$\mathrm{TE} \leftarrow$ '*',

F[n], TEMPO[n], DF[n], TG[n], TC[n], TFmaior[n], TFmenor[n]; vetor de

DELTR $\leftarrow$ '*',

$z \leftarrow \frac{T E}{D E L T}$,

$\mathrm{n} \leftarrow 0$,

TFmaior $[\mathrm{n}] \leftarrow 0$,

TFmenor $[\mathrm{n}] \leftarrow 0$,

TEMPO $[\mathrm{n}] \leftarrow 0$,

$\mathrm{DF}[\mathrm{n}] \leftarrow 0$,

$\mathrm{TG}[\mathrm{n}] \leftarrow 1$,

$\mathrm{GT} \leftarrow$ ‘*’,

$\mathrm{GP} \leftarrow$ '*',

$\mathrm{GR} \leftarrow$ GT $-\mathrm{GP}$,

! recebe dos dados de entrada o tempo de simulação.

! recebe dos dados de entrada o tempo de cálculo.

! cálculo do $\mathrm{n}^{\circ}$ de iterações que o programa fará.

! fator de iteração do vetor: armazenamento de freqüências.

$\mathrm{TC}[\mathrm{n}] \leftarrow \frac{G T}{G R}$,

! recebe o tempo que a frequiência ficou acima da permitida.

! para a $1^{\circ}$ iteração recebe o valor 0 .

! recebe o tempo que a frequiência ficou abaixo da permitida.

! para a $1^{\circ}$ iteração recebe o valor 0 .

! recebe o tempo em que o programa está em execução.

! recebe a taxa de variação para cada iteração.

! recebe o conjugado mecânico da geração .

! para a $1^{\circ}$ iteração recebe 1 .

! recebe dos dados de entrada a geração total.

! recebe dos dados de entrada a geração perdida.

! geração restante.

! sobrecarga imposta.

$\mathrm{SBC} \leftarrow(T C[n]-1) \times 100, \quad$ ! sobrecarga imposta em \%.

$\mathrm{H} \leftarrow$ '*', $\quad$ ! constante de inércia equivalente das

BMVA $\leftarrow$ '*',

$\mathrm{H} \leftarrow \frac{H \times B M V A}{G R}$,

! máquinas restantes colocadas na mesma base.

$\mathrm{j} \leftarrow 0$,

$\mathrm{FI} \leftarrow$ '*',

$\mathrm{F}[\mathrm{n}] \leftarrow \mathrm{FI}$,

CONST $\leftarrow \frac{F I}{2 H}$,

$\mathrm{i} \leftarrow 1$,

INTO[i] $\leftarrow 0$,

$\mathrm{TX}[\mathrm{i}] \leftarrow 0$,

! base utilizada no cálculo da constante de inércia equivalente.

TOD $\leftarrow 0$,

! constante de inércia em 'pu' cuja base é GR.

! desabilita cálculo de tempo para abertura de relé.

! recebe dos dados iniciais o valor da freqüência inicial.

! valor da freqüência inicial para a $1^{\circ}$ iteração recebe o valor da

! freqüência inicial.

Execute: PROCEDIMENTO I,

Escreva: F[n], TEMPO[n], DF[n], TG[n], TC[n], TFmaior[n], TFmenor[n]; vetor onde n: $0 \rightarrow \mathrm{z}$.

Escreva: INTO[i], TX[i]; vetor onde i: $1 \rightarrow \mathrm{u}$.

Escreva: menorF, maiorF;

FIM PROGRAMA 
PROCEDIMENTO I: Cálculo das frequiências x tempo.

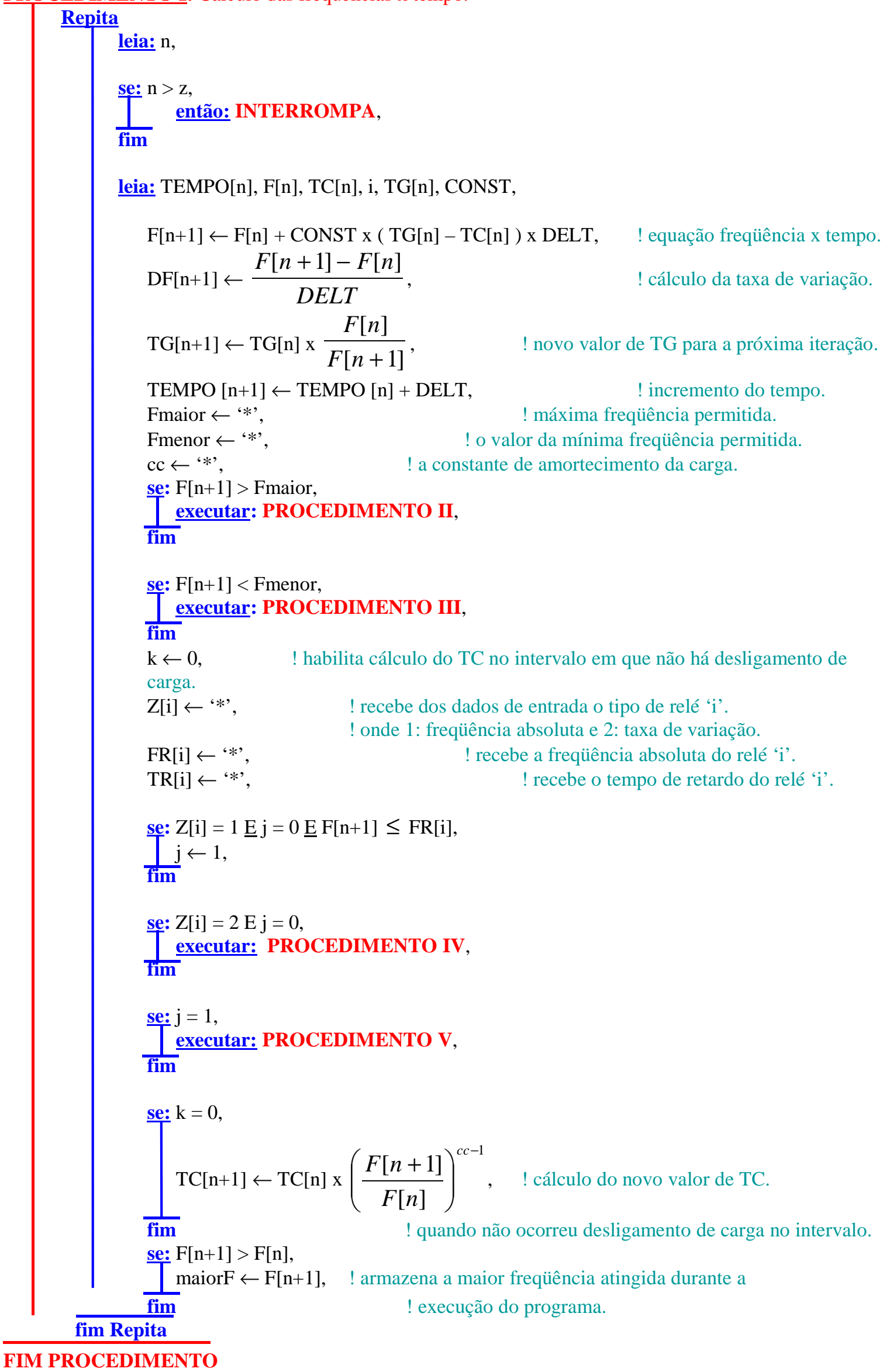


PROCEDIMENTO II: Cálculo da freqüência acumulada acima da permitida até o instante n.

TFmaior $[\mathrm{n}+1] \leftarrow$ TFmaior $[\mathrm{n}]+$ DELT,

$\overline{\text { FIM PROCEDIMENTO }}$

PROCEDIMENTO III: Cálculo da freqüência acumulada abaixo da permitida até o instante n.

TFmenor $[\mathrm{n}+1] \leftarrow$ TFmenor $[\mathrm{n}]+$ DELT

se: $F[n+1]<F[n]$,

menorF $\leftarrow \mathrm{F}[\mathrm{n}+1], \quad$ ! armazena a menor freqüência atingida.

$\overline{\text { fim }}$

FIM PROCEDIMENTO

PROCEDIMENTO IV: Disparo do relé de taxa de variação

$\mathrm{TV}[\mathrm{i}] \leftarrow$ '*', $\quad$ ! recebe dos dados de entrada a taxa de variação do relé 'i'.

$\mathrm{FX}[\mathrm{i}] \leftarrow$ '*', $\quad$ ! recebe dos dados de entrada a freqüência de supervisão do relé 'i'.

$\mathrm{s} \leftarrow 0$,

! permite fixar o tempo e a frequiência em que foi superada a

! freqüência de corte.

$\mathrm{FY}[\mathrm{i}] \leftarrow$ '*',

! recebe dos dados de entrada a frequiência de corte do relé 'i'.

$\mathrm{TX}[\mathrm{i}] \leftarrow 0$, ! vetor que receberá a taxa de variação quando do dispara o relé 'i'.

se: $F[n+1] \leq F X[i] \underline{E} s=0$,

! comparando com a freqüência de supervisão.

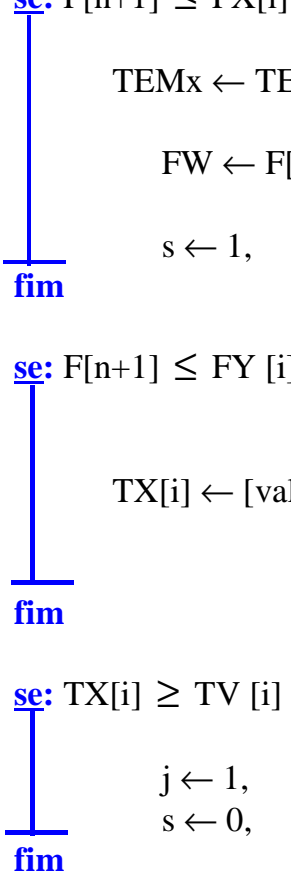

FIM PROCEDIMENTO 


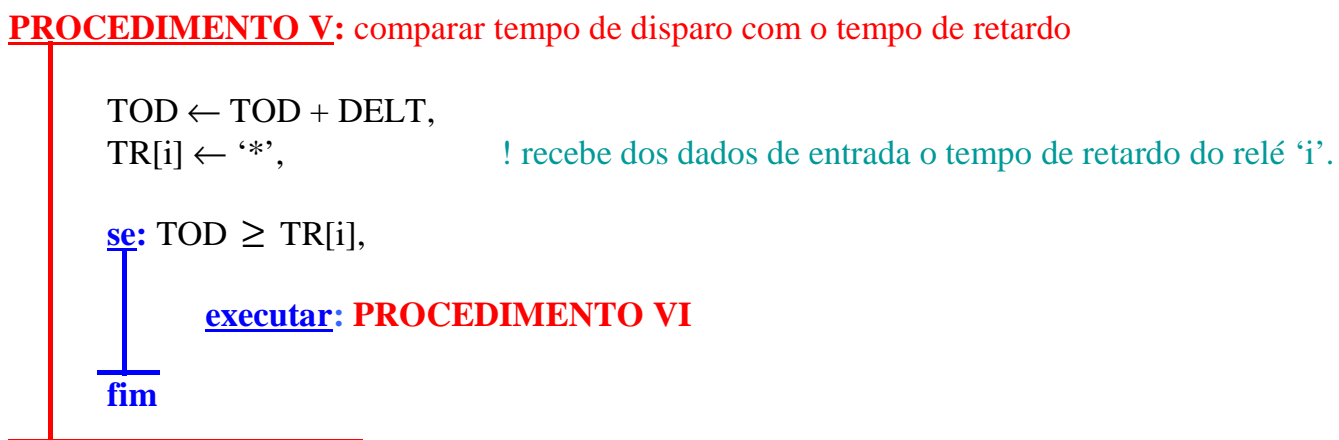

FIM PROCEDIMENTO

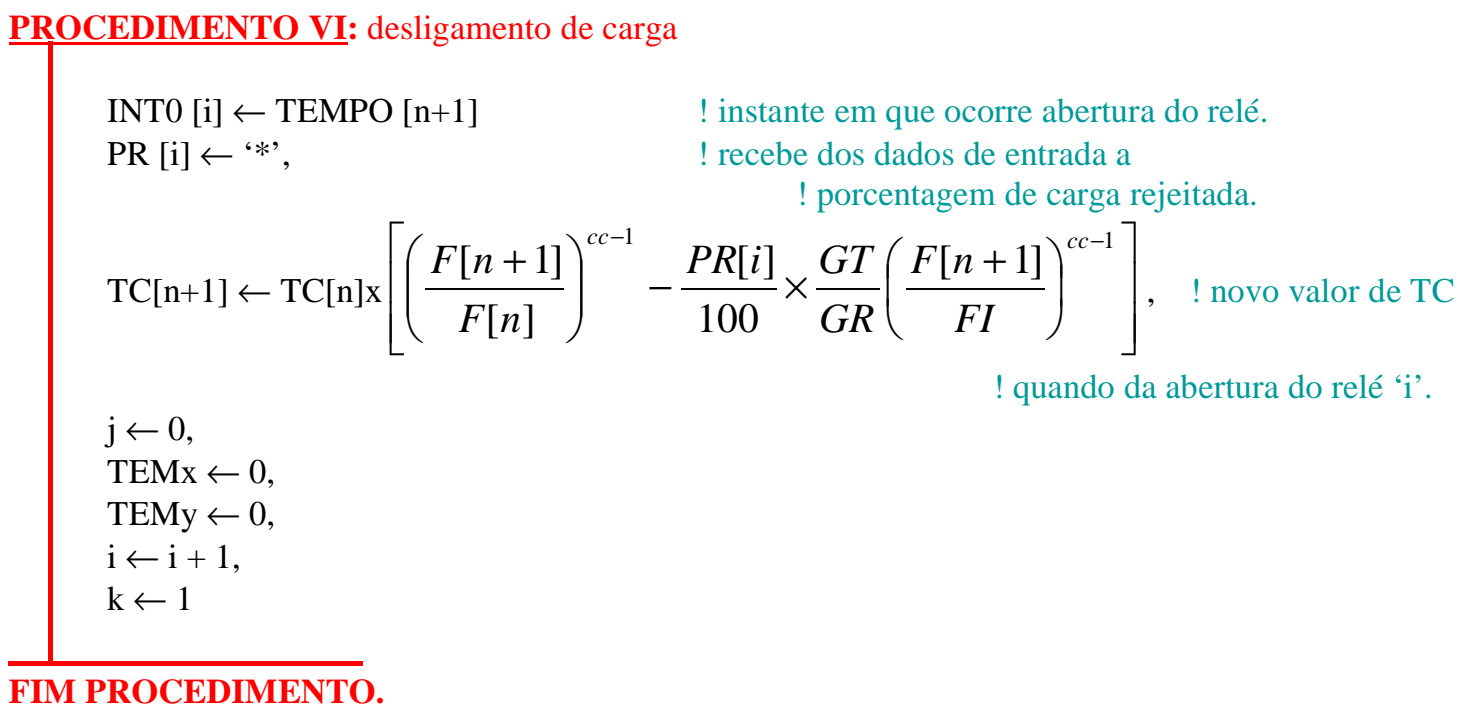




\section{ANEXO II - RESULTADOS EXIBIDOS PELO PROGRAMA VARF-5}

A tabela seguinte é uma reprodução do relatório de saída do programa Varf-5

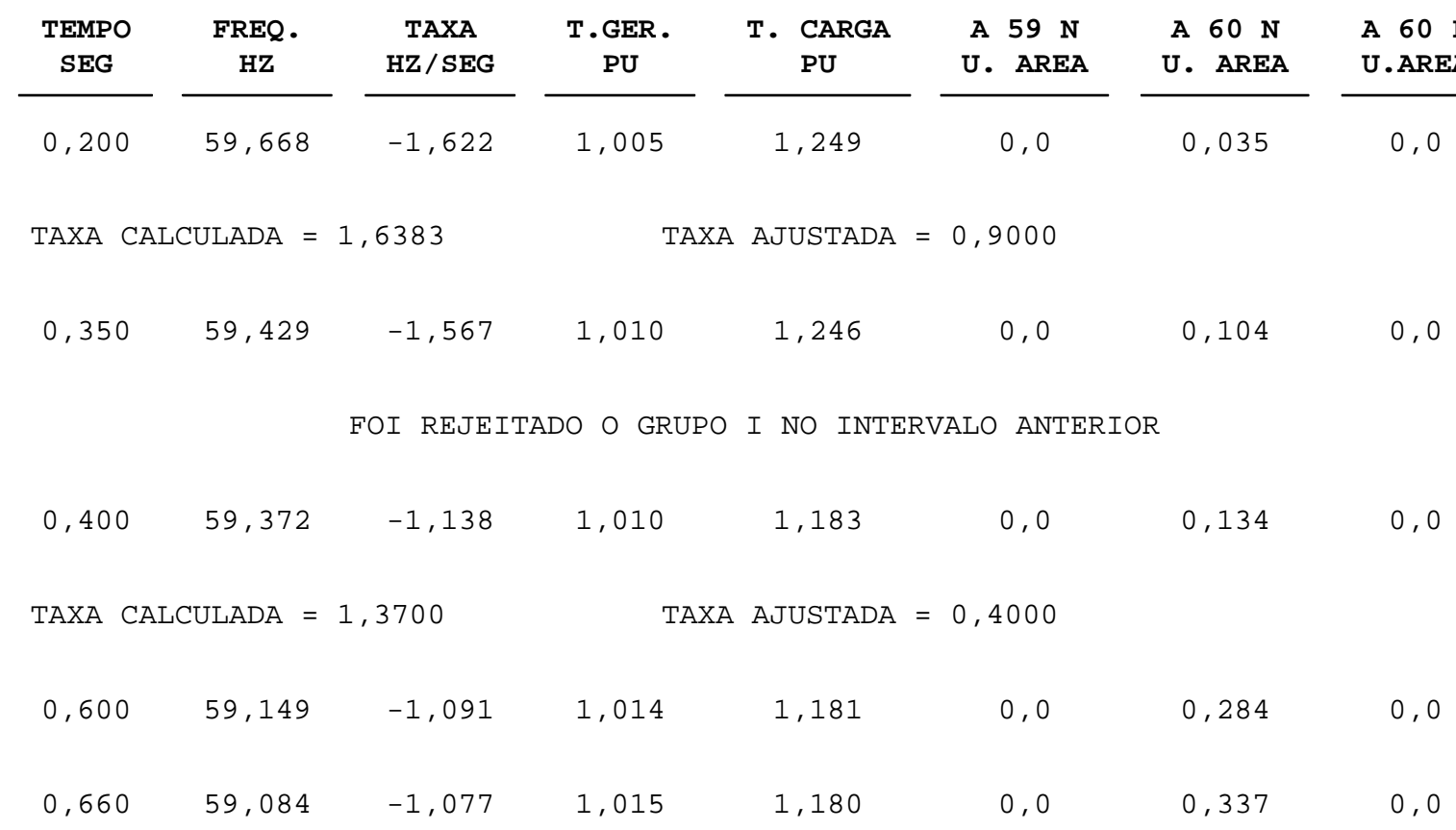

FOI REJEITADO O GRUPO II NO INTERVALO ANTERIOR

$\begin{array}{llllllll}0,800 & 58,992 & -0,648 & 1,017 & 1,116 & 0,000 & 0,472 & 0,0 \\ 1,000 & 58,865 & -0,624 & 1,019 & 1,115 & 0,015 & 0,687 & 0,0 \\ 1,200 & 58,743 & -0,600 & 1,021 & 1,114 & 0,055 & 0,927 & 0,0 \\ 1,210 & 58,737 & -0,600 & 1,021 & 1,114 & 0,058 & 0,939 & 0,0\end{array}$

FOI REJEITADO O GRUPO III NO INTERVALO ANTERIOR

$\begin{array}{llllllll}1,400 & 58,701 & -0,188 & 1,022 & 1,051 & 0,111 & 1,183 & 0,0 \\ 1,600 & 58,564 & -0,182 & 1,023 & 1,051 & 0,175 & 1,447 & 0,0 \\ 1,800 & 58,628 & -0,174 & 1,023 & 1,050 & 0,246 & 1,718 & 0,0 \\ 2,000 & 58,594 & -0,169 & 1,024 & 1,050 & 0,324 & 1,996 & 0,0 \\ 2,200 & 58,561 & -0,163 & 1,024 & 1,050 & 0,409 & 2,280 & 0,0 \\ 2,400 & 58,529 & -0,157 & 1,025 & 1,049 & 0,500 & 2,572 & 0,0 \\ 2,600 & 58,498 & -0,151 & 1,026 & 1,049 & 0,597 & 2,869 & 0,0\end{array}$




$\begin{array}{rrrrrrrr}2,800 & 58,468 & -0,146 & 1,026 & 1,049 & 0,701 & 3,173 & 0,0 \\ 3,000 & 58,440 & -0,142 & 1,027 & 1,049 & 0,810 & 3,482 & 0,0 \\ 3,200 & 58,412 & -0,137 & 1,027 & 1,048 & 0,925 & 3,797 & 0,0 \\ 3,390 & 58,386 & -0,133 & 1,027 & 1,048 & 1,039 & 4,101 & 0,0\end{array}$

FOI REJEITADO O GRUPO IV NO INTERVALO ANTERIOR

$\begin{array}{rrrrrrrr}3,400 & 58,390 & 0,348 & 1,027 & 0,973 & 1,046 & 4,117 & 0,0 \\ 3,600 & 58,458 & 0,337 & 1,026 & 0,974 & 1,160 & 4,432 & 0,0 \\ 3,800 & 58,524 & 0,327 & 1,025 & 0,974 & 1,262 & 4,734 & 0,0\end{array}$

4,000

0,0 